\title{
Assessing oxidative stress resulting from environmental exposure to metals (Oids) in a middle Eastern population
}

\author{
Ata Rafiee - Juana Maria Delgado-Saborit - Noel J. Aquilina - Hoda Amiri • \\ Mohammad Hoseini (i)
}

Received: 1 March 2021 / Accepted: 4 August 2021

(C) The Author(s), under exclusive licence to Springer Nature B.V. 2021

\begin{abstract}
Concentrations of metals and metalloids derived mainly from anthropogenic activities have increased considerably in the environment. Metals might be associated with increase reactive oxygen species (ROS) damage, potentially related to several health outcomes. This study has recruited 200 adult participants, including 110 males and 90 females in Shiraz (Iran), to investigate the relationship between chronic exposure to metals and ROS damage by analyzing malondialdehyde (MDA) and 8-Oxo-2'-
\end{abstract}

Supplementary Information The online version contains supplementary material available at https://doi.org/10.1007/ s10653-021-01065-z.

\section{A. Rafiee}

Department of Medicine, University of Alberta,

Edmonton, AB, Canada

J. M. Delgado-Saborit

Perinatal Epidemiology, Environmental Health and

Clinical Research, School of Medicine, Universitat Jaume

I, Castellon, Spain

J. M. Delgado-Saborit

ISGlobal Barcelona Institute for Global Health, Barcelona

Biomedical Research Park, Barcelona, Spain

J. M. Delgado-Saborit

Population Health and Environmental Sciences,

Analytical Environmental and Forensic Sciences, King's

College London, London, UK deoxyguanosine (8-OHdG) concentrations, and has evaluated the associations between chronic metal exposure and ROS damage using regression analysis. Our findings showed participants are chronically exposed to elevate $\mathrm{As}, \mathrm{Ni}, \mathrm{Hg}$, and $\mathrm{Pb}$ levels. The mean urinary concentrations of $8-\mathrm{OHdG}$ and MDA were $3.8 \pm 2.35$ and $214 \pm 134 \mu \mathrm{g} / \mathrm{g}$ creatinine, respectively. This study shows that most heavy metals are correlated with urinary ROS biomarkers ( $R$ ranges 0.19 to 0.64 ). In addition, regression analysis accounting for other confounding factors such as sex, age, smoking status, and teeth filling with amalgam highlights that $\mathrm{Al}, \mathrm{Cu}, \mathrm{Si}$ and $\mathrm{Sn}$ are associated with

\section{J. M. Delgado-Saborit}

Division of Environmental Health \& Risk Management, School of Geography, Earth \& Environmental Sciences, University of Birmingham, Birmingham, UK

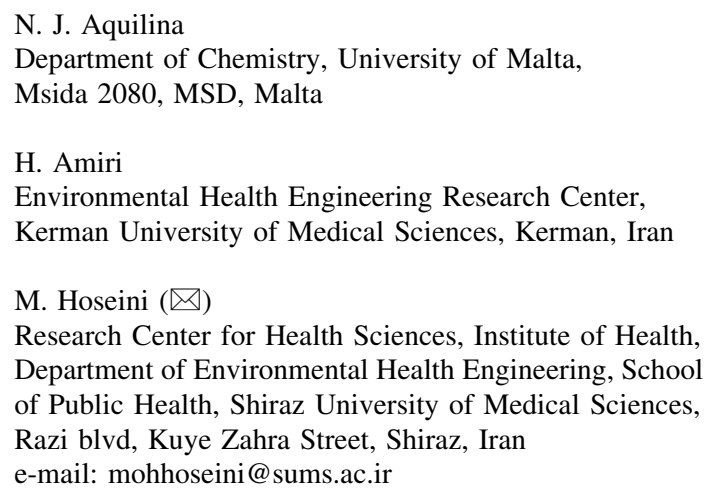
Department of Environmental Health Engineering, School of Public Health, Shiraz University of Medical Sciences, Razi blvd, Kuye Zahra Street, Shiraz, Iran e-mail: mohhoseini@sums.ac.ir 
8-OHdG concentrations, while an association between $\mathrm{Cr}$ and MDA and 8-OHdG is suggested. Smoking cigarettes and water-pipe is considered a significant contributory factor for both ROS biomarkers (MDA and 8-OHdG).

Keywords Biomonitoring - Heavy metals - MDA . Oxidative damage $\cdot 8-\mathrm{OHdG}$

\section{Introduction}

Anthropogenic activities such as manufacturing of metal products, industrial activities, combustion of fossil fuel, fireworks (Lin, 2016), and generation of electronic waste (Venugopal et al., 2016) have dramatically increased during recent decades on a global scale (Zhu et al., 2018). As a consequence, the levels of metals and metalloids elements derived mainly from these activities have increased considerably in the environment (Liu et al., 2015; Zhu et al., 2018). Two sources of comparable contribution to metals and metalloids-laden fine and coarse particulate matter, especially in cities with trafficked urban areas, are motor vehicle tailpipe exhaust and nonexhaust emissions (Al Hanai et al., 2019; Gietl et al., 2010; Harrison et al., 2001; Lenschow et al., 2001; Querol et al., 2004). The latter are associated with brake wear, road wear, tyre wear and road dust resuspension (Amato et al., 2014, 2016; Boogaard et al., 2011; Denier van der Gon et al., 2013; Keuken et al., 2013; Querol et al., 2007; Thorpe \& Harrison, 2008). While the tailpipe exhaust typically contains $\mathrm{Pd}, \mathrm{Rh}$ and $\mathrm{Pt}$, the non-exhaust emitted particles contain a complex mixture of metals and metalloids and some of them are used as markers. $\mathrm{Zn}$ is typically associated with tyre wear, $\mathrm{Fe}, \mathrm{Sb}, \mathrm{Sn}, \mathrm{Cu}, \mathrm{Ba}$ are dominant in brake wear, while $\mathrm{Fe}, \mathrm{Ti}, \mathrm{Ca}, \mathrm{K}, \mathrm{Cs}, \mathrm{Al}$, $\mathrm{Rb}, \mathrm{Cs}$ are commonly found in re-suspended dust (Kwak et al., 2013; Lawrence et al., 2013; Varrica et al., 2013). Some essential elements play an important role in human health at specific concentrations, including transport of proteins, improvement of enzymes' activity and structure, and other biological system functions (Amaral et al., 2008). Selenium (Se), for example, serves as a fundamental trace element in children's growth and in protecting cells against oxidative damage (Fábelová et al., 2018; Ventura et al., 2005). Zinc ( $\mathrm{Zn})$ is an intracellular element engaged in DNA repair and genetic stability, and copper $(\mathrm{Cu})$ is involved in the immune system and the development of collagen's neuronal connections and synthesis (Amaral et al., 2008). On the other hand, some metals and metalloids are toxic and accumulate in internal organs (Gil \& Hernandez Jerez, 2009; Molina-Villalba et al., 2015). Cadmium (Cd) is a known carcinogenic (Group I) heavy metal, and chronic exposure is toxic to the kidneys (Satarug \& Moore, 2004). Arsenic (As) and lead ( $\mathrm{Pb}$ ) are ranked at the top of the list of the Agency for Toxic Substances and Disease Registry (ATSDR, 2013). Studies revealed heavy metals are neurotoxic and associated with impairment of the central nervous system (Chen et al., 2016). Moreover, some studies reported the association between metals exposure with detriments in attention and executive function (Bowler et al., 2007; Rafiee et al., 2020; Soetrisno \& DelgadoSaborit, 2020).

The mechanisms mediating metals' toxic effects are multifactorial, but oxidative stress is suggested as one important pathway (Almeida Lopes et al., 2017). Metals generate reactive oxygen species (ROS) such as hydroxyl radicals $\left(\mathrm{OH}^{-}\right)$and non-radical species such as hydrogen peroxide $\left(\mathrm{H}_{2} \mathrm{O}_{2}\right)$ (Halliwell \& Cross, 1994) through Fenton reactions (Domingo-Relloso et al., 2019). Metal-induced ROS might lead to an imbalance in the antioxidant system, subsequently causing lipid peroxidation and cellular injury (Farmand et al., 2005). Early biological effects of ROS might be detected by increased levels of malondialdehyde (MDA), a marker of lipid peroxidation, (mainly associated with cellular membrane damage) and 8-Hydroxydeoxyguanosine (8-OHdG), also known as 8-Oxo-2'-deoxyguanosine (8-oxo-dG), a marker of DNA damage (Domingo-Relloso et al., 2019; Teichert et al., 2009).

Human biomonitoring (HBM) has been widely used as a reliable approach in human exposure assessment in the general population and occupational settings (Hoseini et al., 2018; Rafiee et al., 2018a, 2018b, 2019). Several biological matrices have been used in biomonitoring studies such as blood (Richmond-Bryant et al., 2014), urine (Hoseini et al., 2018; Rafiee et al., 2018a), serum (Alimonti et al., 2007; Skalny et al., 2017), plasma (Vural et al., 2010), nails (Carneiro et al., 2011; Coelho et al., 2013), and hair (Fábelová et al., 2018; Luo et al., 2014; Rafiee 
et al., 2020; Soetrisno \& Delgado-Saborit, 2020; Varrica et al., 2014; Zhu et al., 2018).

Because of some advantages over urine and blood, such as the high capacity to accumulate metals and metalloids over long-time periods, using hair allows researchers to monitor past and ongoing exposure to these pollutants (Amaral et al., 2008; Luo et al., 2014; Pan \& Li, 2015). Moreover, hair is considered a noninvasive matrix and its transport, preparation, and analysis are more convenient than blood or urine (Drobyshev et al., 2017; Sazakli \& Leotsinidis, 2017a; Zhu et al., 2018). Numerous biomonitoring studies have been investigating the exposure of the general population to metals and metalloids using hair, and in different countries such as Pakistan (Eqani et al., 2018), Russia (Skalny et al., 2015a, 2015b), China (Li et al., 2014), Nigeria (Nnorom et al., 2005), Iran (Rafiee et al., 2020) and Egypt (Saad \& Hassanien, 2001). Some studies have focused on children and adolescents as sensitive population sub-groups (Drobyshev et al., 2017; Fábelová et al., 2018; Molina-Villalba et al., 2015; Peña-Fernández et al., 2014; Soetrisno \& Delgado-Saborit, 2020; Varrica et al., 2014). In addition, some studies have investigated the impact of environmental metals and metalloids exposure, such as living in mining areas (Barbieri et al., 2011; Pan \& Li, 2015), industrialized areas (Nnorom et al., 2005) and near e-waste facilities (Soetrisno \& Delgado-Saborit, 2020). Some other studies have investigated the effect of diet and lifestyle as potential factors affecting the variability of metal and metalloid concentrations in the human scalp hair (Shao et al., 2017; Zhu et al., 2018). In addition, some studies have investigated the association between short-term exposures and oxidative stress (Almeida Lopes et al., 2017; Bortey-Sam et al., 2018; DomingoRelloso et al., 2019), but studies on the effect of chronic exposure to metals and metalloids and oxidative stress biomarkers in the general population are scarce, and even more in the general population in low- and middle-income countries. With this in mind, the present study aimed to:

1. characterize exposure to metals and metalloids in scalp hair samples from residents of Shiraz, Iran;

2. investigate factors that could have a potential impact on metals and metalloids levels in hair, including sex, age as well as environmental and lifestyle factors; and
3. assess the relationship between the levels of oxidative stress biomarkers, including malondialdehyde (MDA) and 8-hydroxy-2'-deoxyguanosine $(8-\mathrm{OHdG})$ in the urine with the corresponding metals and metalloids levels in the hair of Shiraz city residents.

\section{Materials and methods}

Study area description

The present cross-sectional study was implemented in Shiraz, the capital of Fars province and the sixth most populous city in Iran, with approximately 1.8 million inhabitants smaller than Tehran, capital of Iran (Mirzaei et al., 2018; Rafiee et al., 2016, 2018b). The city is enclosed by the mountains on its North, East, and Southeast sides, restricting air circulation. In addition, there is an industrial park on the Southside of the city, which along with traffic congestion, has contributed to elevating air pollution in the city (Mirzaei et al., 2018; Shahsavani et al., 2017).

\section{Subjects recruitment}

The cohort in this study comprised 110 males and 90 females, aged between 15 to 70, who were randomly selected to participate if they satisfied a set of criteria. Detailed information on the study recruitment are provided in Rafiee et al., (2020). Briefly, the inclusion criteria required the subjects to be healthy with no chronic conditions, not occupationally exposed to metals and metalloids and must have been living in Shiraz's urban area for the last decade. In addition, given the study's nature, the subjects were required to have hair longer than $5 \mathrm{~mm}$. Pregnant and breastfeeding women were excluded.

Following approved written consent to take part in this study, scalp hair samples were collected from participants to be analyzed for metals and metalloids concentrations and urine samples to be analyzed for markers of oxidative stress, including MDA and 8-OHdG. The Ethical Committee approved the present study at the Shiraz University of Medical Sciences (IR.SUMS.REC.1398.320). 
Hair sampling and metals and metalloids identification

Hair sampling was performed in June 2019 during the subjects' visits to the hairdresser salons for haircuts. Around $2.5 \mathrm{~g}$ of hair from 1 to $1.5 \mathrm{~cm}$ of each subject's scalp in both groups was collected using stainless-steel scissors (Rafiee et al., 2020). Hair samples were then stored in labeled polyethylene zip bags and sent to the laboratory for further analysis. Hair samples cleaning was performed based on the procedures developed by the International Atomic Energy Agency (IAEA). The method included dispersing hair samples in acetone for $10 \mathrm{~min}$, followed by washing with ultra-pure water (Milli-pore, MA, France) and then washed with acetone. Detailed information on sample preparation and the digestion method was described in our previous work (Rafiee et al., 2020). Briefly, nitric acid $65 \%$ and perchloric acid $70 \%$ (Merck, Darmstadt Germany) were used for digestion. $100 \mathrm{mg}$ sample was microwave digested using a nitric acid-perchloric acid V/V 3:1 solution and then diluted with $18 \mathrm{M} \Omega \mathrm{cm}$ demineralized water. The microwave digestion program is given in Table S1 (Supplementary information).

Quantification of 17 selected metals and metalloids, including $\mathrm{Al}, \mathrm{As}, \mathrm{Cd}, \mathrm{Cr}, \mathrm{Hg}, \mathrm{Fe}, \mathrm{Mn}, \mathrm{Cu}, \mathrm{Pb}, \mathrm{Zn}, \mathrm{B}$, $\mathrm{Ni}, \mathrm{Be}, \mathrm{Sb}, \mathrm{Ba}, \mathrm{Li}$, and $\mathrm{Sn}$ was performed using Inductively Coupled Plasma Optical Emission Spectrometry (ICP-OES) with EOP flared end torch $2.5 \mathrm{~mm}$ (SPECTRO Analytical Instruments Inc. Germany). Details of the ICP-OES operating setup, as well as quality assurance and quality control protocols, are presented in Table S2 and S3, respectively.

Determination of oxidative stress markers in urine samples

The levels of MDA and 8-OHdG were determined in urine samples collected from the participants to investigate the relationship between environmental metals and metalloids exposure and markers of oxidative stress. Spot urine samples were collected in the middle of the day from subjects who donated hair samples. Urine samples were collected in polypropylene bottles, wrapped in foil, and stored at $4{ }^{\circ} \mathrm{C}$ in a portable fridge and transferred immediately to the laboratory for further analysis. At the laboratory, urine samples were first centrifuged at $1500 \mathrm{rpm}$ for
10 min, and then supernatants were collected. Both markers were corrected for creatinine, determined by the Jaffé reaction method (Butler, 1975). The MDA equivalents were quantified from the formation of thiobarbituric acid reactive substances because of the lipid peroxidation in urine according to the method described in Chatziargyriou and Dailianis (2010). In summary, about $500 \mu \mathrm{L}$ of urine was exposed to phorbol-myristate acetate (PMA) $\left(10 \mu \mathrm{g} \mathrm{mL}^{-1}\right)$. The samples were then centrifuged at $1200 \mathrm{rpm}$ for $10 \mathrm{~min}$ at $4{ }^{\circ} \mathrm{C}$ and the supernatant was removed. After vortexing for $5 \mathrm{~s}$, butylated hydroxytoluene (BHT) at a concentration of $0.02 \%$ was added to prevent further lipids' peroxidation. In the last stage, the samples were incubated at $90-100{ }^{\circ} \mathrm{C}$ for $15 \mathrm{~min}$ and cooled at room temperature, centrifuged at $10,000 \mathrm{rpm}$ for $10 \mathrm{~min}$ and measured spectrophotometrically at $535 \mathrm{~nm}$.

Oxidative stress ELISA kit (Zell Bio, GmbH., Germany) was used to determine the concentration of 8-OHdG in the urine based on the method described elsewhere (Ściskalska et al., 2014). In brief, $100 \mu \mathrm{L}$ of conjugate $8-\mathrm{OHdG} /$ bovine serum albumin (BSA) were added to each of the 96-well plates of the ELISA kit and incubated overnight at $4{ }^{\circ} \mathrm{C}$ and washed with water, followed by $200 \mu \mathrm{L}$ blocking buffer and incubated for $1 \mathrm{~h}$ at room temperature. $50 \mu \mathrm{L}$ of samples and $50 \mu \mathrm{L} 8$-OHdG standards were added, and after 10 min of incubation, $100 \mu \mathrm{L}$ of monoclonal anti-8-OHdG was added and incubated for $1 \mathrm{~h}$ at room temperature, then washed three times by the addition of secondary antibody conjugated to $100 \mu \mathrm{L}$ of horseradish peroxidase, followed by 1 -h incubation at room temperature. Next, $100 \mu \mathrm{L}$ of substrate for peroxidase was added to the plate and incubated for $20 \mathrm{~min}$. Then, $100 \mu \mathrm{L}$ of reaction stop solution was added. Absorbance was spectrophotometrically measured at a wavelength of $450 \mathrm{~nm}$. The amount of 8 -OHdG was calculated by comparison with a standard curve determined from standards treated similarly to the samples.

\section{Questionnaire to assess potential confounders}

The subjects were given a questionnaire to identify possible confounders of chronic metals and metalloids exposure based on a previous study (Rafiee et al., 2020) to self-report their demographic (age, sex, height, weight, BMI), socioeconomic and health (types of diet, use of health supplements) status. In 
addition, lifestyle characteristics that influence their environmental exposure (cigarette and water-pipe smoking, environmental tobacco smoke, amalgam tooth filling, traffic density near home, frequency of hair product use, insecticide use) were also collected.

\section{Statistical approach}

In this study, SPSS 21.0 package software (SPSS Inc. Chicago, IL) and Graph Pad Prism software 8.0 were used to perform statistical analysis on metals and metalloids data in hair samples and oxidative stress markers in urine samples. The normality of the data distribution was performed using the KolmogorovSmirnov test. Sociodemographic and environmental differences according to sex were assessed with an independent t-test for numeric variables and the Chisquared test for categorical ones. Mann-Whitney U test was employed to assess differences in metals and metalloids levels in hair and markers of oxidative stress among studied groups. Multiple linear regression analysis was applied to evaluate the association between concentrations of oxidative stress biomarkers and individual metals and metalloids levels in hair samples and covariate factors including sex, age, smoking status, and teeth filling with amalgam.

Oxidative stress biomarkers concentrations were treated as continuous variables (MDA per $1 \mu \mathrm{mol} / \mathrm{mol}$ creatinine and 8 -OHdG per $1 \mathrm{ng} / \mathrm{mmol}$ creatinine). Individual metals and metalloids concentrations in hair samples were considered continuous variables (per $1 \mu \mathrm{g} / \mathrm{g}$ ). Covariates were considered categorical for sex (male/female), cigarette smoking (no/yes), water-pipe smoking (no/yes), and teeth filling with amalgam (no/yes). Age was considered a continuous variable (per 1 year). Collinearity between variables was analyzed by conducting the spearman correlation test. The pairwise correlation coefficient $(r)$ of $<0.5$ was used as the indicator for introducing variables in the model. To perform the multiple linear regression model, we first checked the model's assumption, including multivariate normality, multicollinearity, and homoscedasticity. The multivariate normality was checked by drawing the P-P plot, and the results show that the residuals of the regression followed a normal distribution. To check the multicollinearity, we checked variance inflation factor (VIF) values. The VIF values were below 10 and in the range of 1.03 to
2.12. The homoscedasticity was checked by plotting the predicted values and residuals on a scatterplot.

\section{Results}

Participants' characterizations

Results of the socio-demographic characterization, health status, and lifestyle habits of the studied men and women participants are shown in Table 1. Significant differences were observed among males and females regarding demographic characterizations such as age, height, weight, and BMI $(P<0.05)$. All participants were educated, and $84 \%$ of them held tertiary education degrees. According to the information gathered from the questionnaires and face-to-face interviews, $44 \%$ of subjects were smokers (cigarettes), and $29 \%$ were water-pipe smokers, with a higher prevalence among males $(p<0.05)$. In addition, 34\% of subjects were classified as passive smokers, with a higher prevalence among women $(p<0.05)$ (Table 1$)$. No sex differences were observed for teeth filling with amalgam $(p>0.05)$, but it was considerably higher among smokers than non-smokers in both male and female participants $(p<0.05)$. The largest proportion of subjects $(58 \%)$ lived in houses with medium residential traffic levels, but more women lived in areas with low residential traffic, compared to men participating in this study $(p<0.05)$. Sex differences were also observed according to hair cosmetic products usage, with $70 \%$ of women reporting to use them every day or once per two days, while only $30 \%$ reported cosmetic usage with that frequency $(p<0.05)$. No sex differences were observed for taking health supplements, with $57 \%$ taking these, nor was observed for fish consumption, with $58 \%$ of subjects reporting eating fish $(p>0.05)$.

Distribution of metals and metalloids concentrations among participants

Results of selected metals and metalloids levels in the hair samples of studied subjects are given in Table 2. The highest and lowest mean metals and metalloids levels were observed for B and As, respectively. The order of mean metals and metalloids levels in the hair samples of the studied subjects was as follows: $\mathrm{B}>\mathrm{Zn}>\mathrm{Al}>\mathrm{Fe}>\mathrm{Si}>\mathrm{Ba}>\mathrm{Cr}>\mathrm{Hg}>\mathrm{Pb}>$ 
Table 1 Socio-demographic characteristics and health status of the participants stratified by sex

\begin{tabular}{|c|c|c|c|c|}
\hline Variables & $\operatorname{Men}(n=110)$ & Women $(n=90)$ & Total $(n=200)$ & $\begin{array}{l}\text { Group differences } \\
p \text {-value }\end{array}$ \\
\hline Age (years) & $38 \pm 10$ & $29 \pm 12$ & $35 \pm 14$ & $<0.0001^{\mathrm{a}}$ \\
\hline Height $(\mathrm{cm})$ & $179 \pm 6$ & $160 \pm 8$ & $172 \pm 8$ & $<0.0001^{\mathrm{a}}$ \\
\hline Weight (kg) & $78 \pm 11$ & $61 \pm 9$ & $70 \pm 13$ & $<0.0001^{\mathrm{a}}$ \\
\hline BMI $\left(\mathrm{kg} / \mathrm{m}^{2}\right)$ & $26 \pm 4$ & $24 \pm 5$ & $24 \pm 4$ & $<0.0019^{\mathrm{a}}$ \\
\hline \multicolumn{4}{|l|}{ Education (\%) } & $0.9156^{\mathrm{b}}$ \\
\hline High school Diploma & 17 & 15 & 16 & \\
\hline Bachelor & 45 & 45 & 45 & \\
\hline Master & 38 & 40 & 39 & \\
\hline \multicolumn{4}{|l|}{ Cigarette smoking (\%) } & $0.0006^{b}$ \\
\hline Yes & 55 & 31 & 44 & \\
\hline No & 45 & 69 & 56 & \\
\hline \multicolumn{4}{|l|}{ Water-pipe smoking $(\%)$} & $0.0389^{b}$ \\
\hline Yes & 31 & 27 & 29 & \\
\hline No & 69 & 73 & 71 & \\
\hline \multicolumn{4}{|c|}{ Environmental tobacco smoke $(\%)$} & $0.0161^{b}$ \\
\hline Yes & 25 & 41 & 34 & \\
\hline No & 75 & 59 & 66 & \\
\hline \multicolumn{4}{|c|}{ Teeth filling with amalgam (\%) } & $0.4335^{\mathrm{b}}$ \\
\hline Yes & 74 & 69 & 72 & \\
\hline No & 26 & 31 & 28 & \\
\hline \multicolumn{4}{|c|}{ Traffic situation near the place of residence (\%) } & $0.0219^{b}$ \\
\hline Low & 20 & 35 & 26 & \\
\hline Medium & 60 & 55 & 58 & \\
\hline High & 20 & 10 & 16 & \\
\hline \multicolumn{4}{|c|}{ Hair cosmetic products usage $(\%)$} & $<0.0001^{\mathrm{b}}$ \\
\hline Everyday & 20 & 25 & 21 & \\
\hline Once per two days & 10 & 45 & 26 & \\
\hline Once a week & 15 & 20 & 18 & \\
\hline Seldom & 55 & 10 & 35 & \\
\hline \multicolumn{4}{|c|}{ Taking health supplement (\%) } & $\mathbf{0 . 0 3 1 8}^{\mathrm{b}}$ \\
\hline Yes & 60 & 53 & 57 & \\
\hline No & 40 & 47 & 43 & \\
\hline \multicolumn{4}{|l|}{ Fish consumption $(\%)$} & $0.4744^{\mathrm{b}}$ \\
\hline Yes & 55 & 60 & 58 & \\
\hline No & 45 & 40 & 42 & \\
\hline
\end{tabular}

a) t-student independent means test; b) Chi-squared test

$\mathrm{Mn}>\mathrm{Cu}>\mathrm{Ag}>\mathrm{Cd}>\mathrm{Ni}>\mathrm{Sn}>$ As. The mean metals and metalloids concentrations were significantly different between men and women participants $(p<0.05)$ for some metals. The mean levels of $\mathrm{Ag}$, $\mathrm{Ba}$, and $\mathrm{Cd}$ were considerably higher in the hair samples of females than males (Mann-Whitney U test, $p<0.05)$. On the other hand, the mean concentrations of $\mathrm{Cr}, \mathrm{Fe}, \mathrm{Ni}, \mathrm{Pb}$, and $\mathrm{Si}$ of males' hair samples were significantly higher than the corresponding values in females (Mann-Whitney $\mathrm{U}$ test, $p<0.05$ ). No 


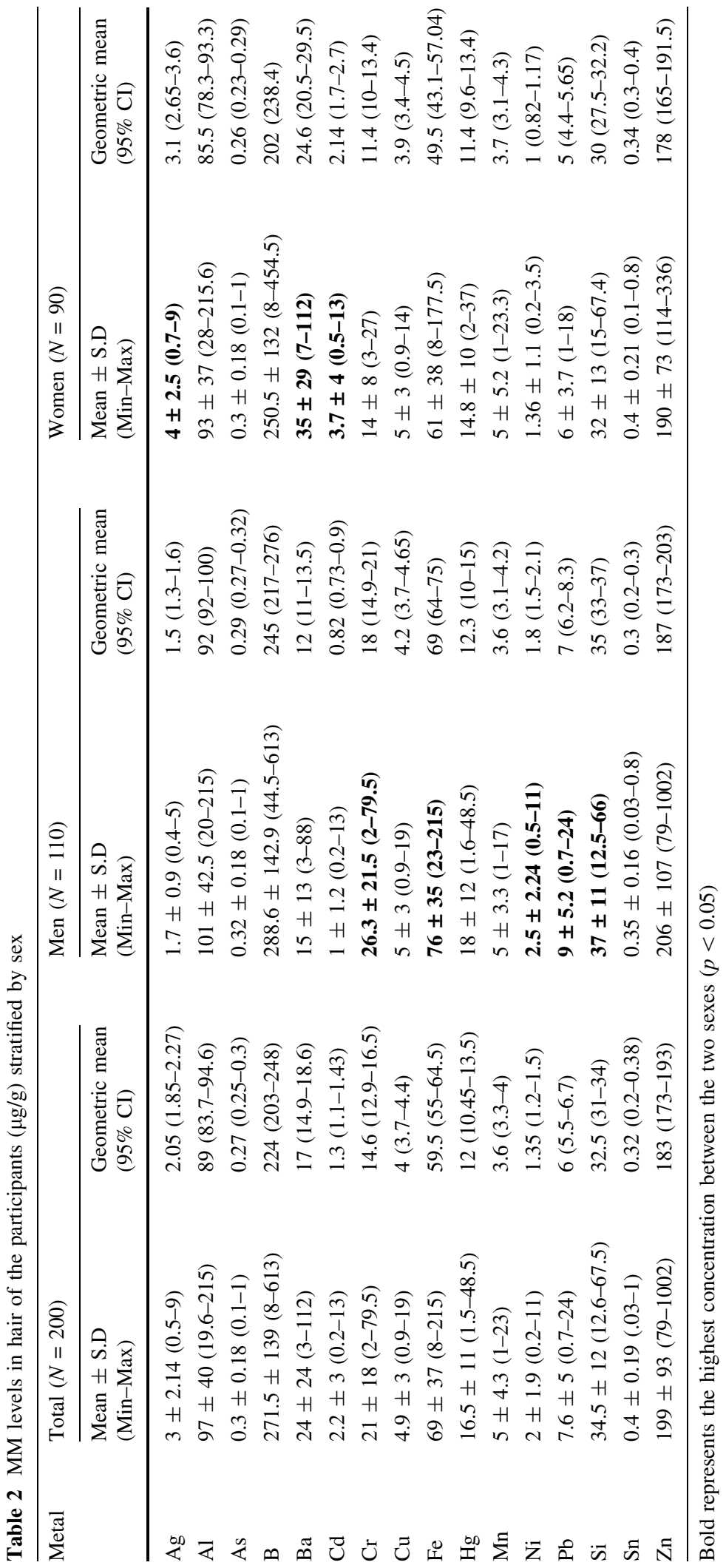


Fig. $1 \mathrm{Ag}$ and $\mathrm{Hg}$ levels in hair of subjects who are smoker/non-smokers and with/without amalgam teeth fillings $(\mu \mathrm{g} / \mathrm{g})$

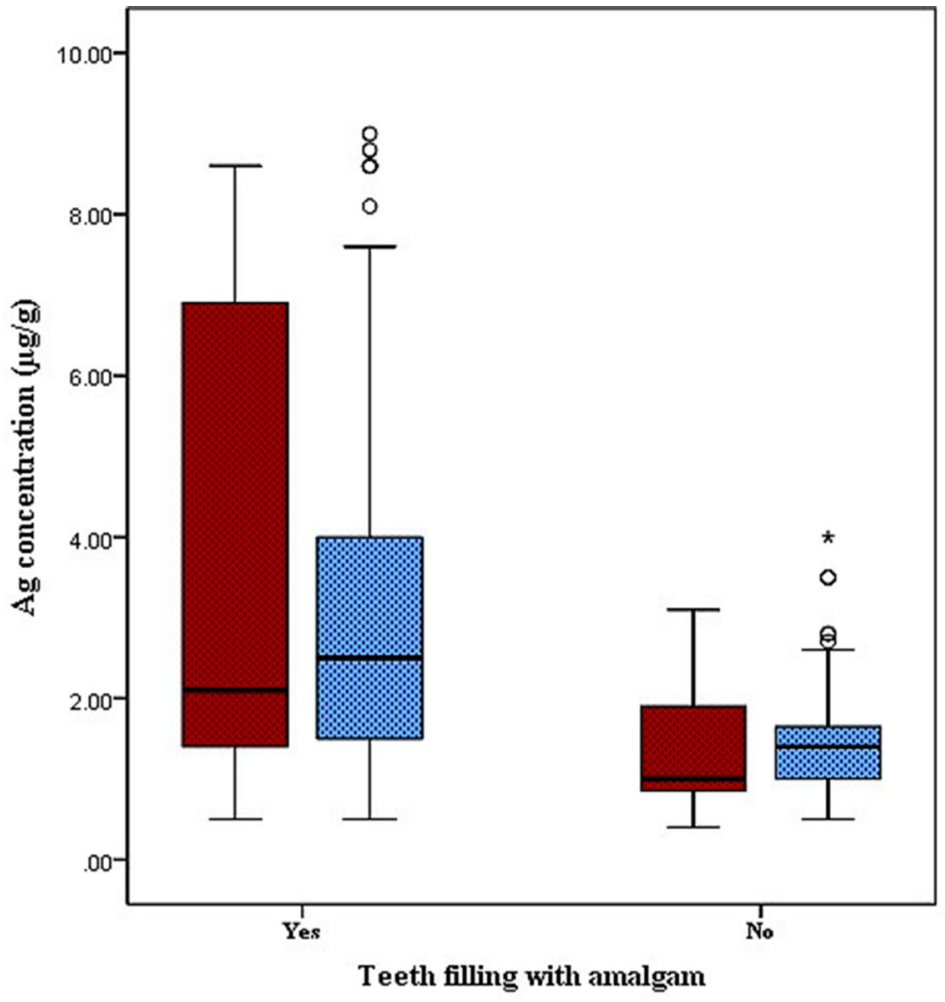

1: Smoker 2: Nont-smoker

눙2

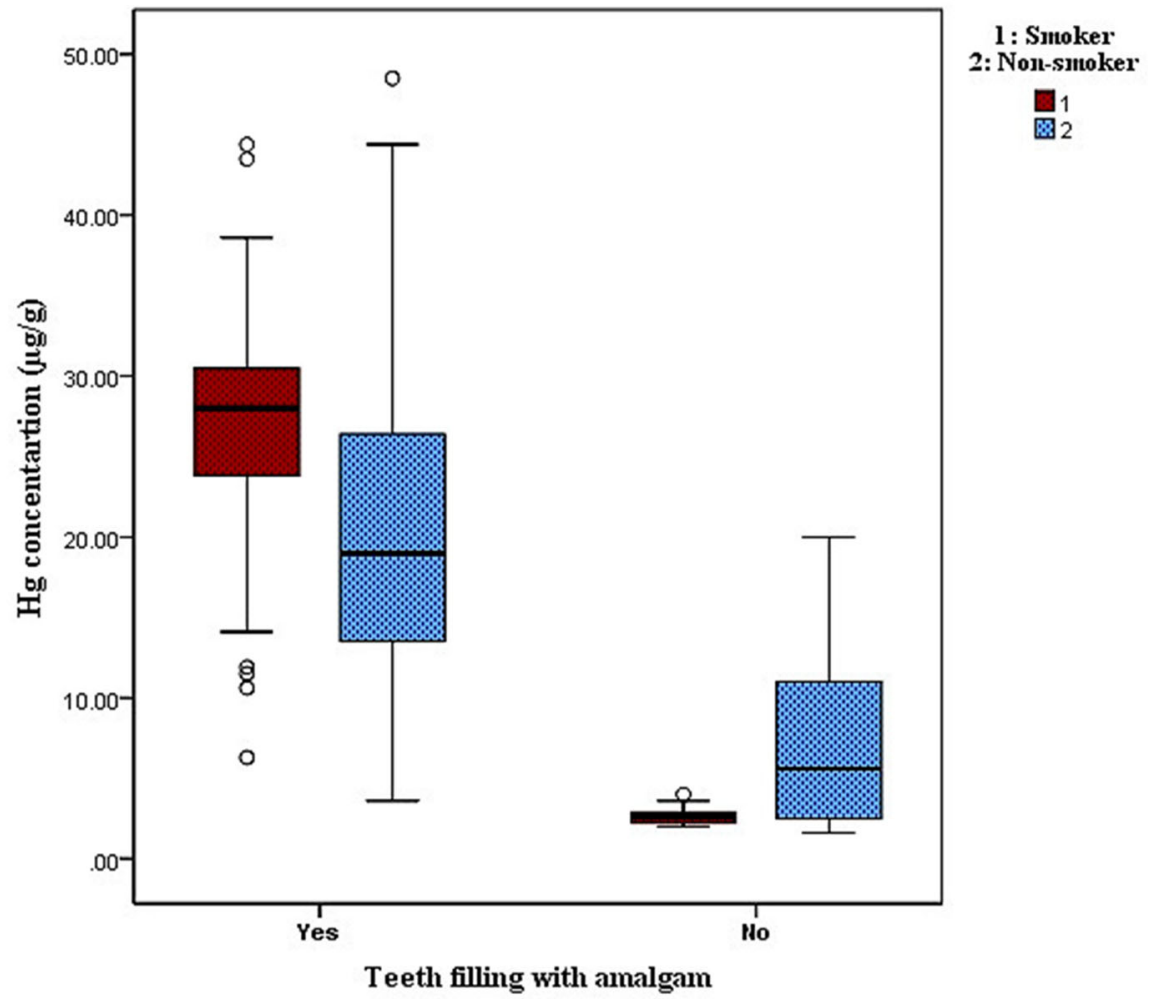



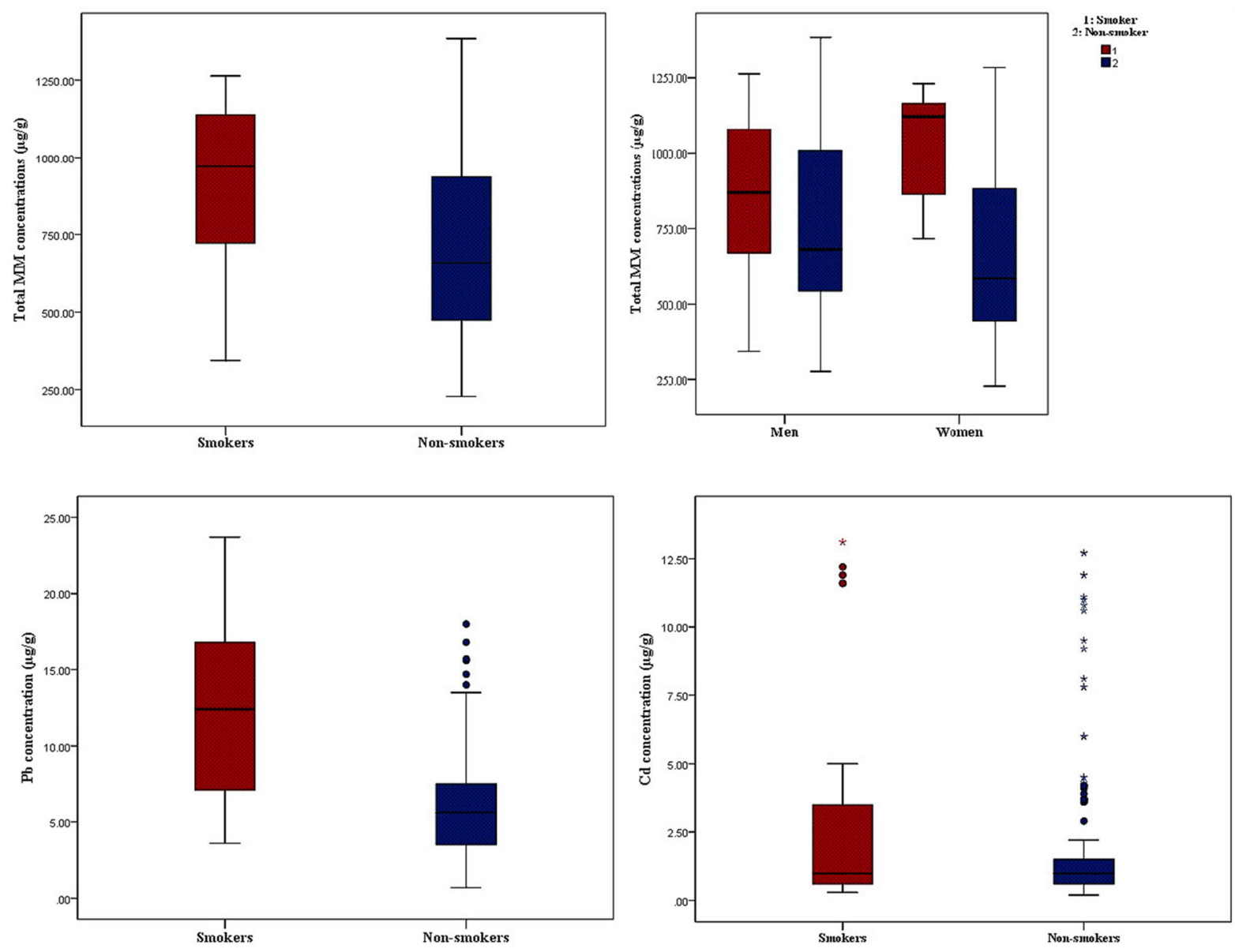

Fig. 2 Sum of metals and metalloids, $\mathrm{Pb}$, and $\mathrm{Cd}$ levels in hair of smoker and non-smoker subjects $(\mu \mathrm{g} / \mathrm{g})$

significant differences were observed for $\mathrm{Al}$, As, B, $\mathrm{Cu}, \mathrm{Hg}, \mathrm{Mn}, \mathrm{Sn}$, and $\mathrm{Zn}$ levels between the studied groups (Mann-Whitney U test, $p>0.05$ ). Levels of $\mathrm{Hg}$ and $\mathrm{Ag}$ in the hair of subjects who had dental amalgam fillings were significantly higher than those with no teeth fillings with amalgam $(p<0.05$, Fig. 1$)$. Figure 2 shows the results of metals and metalloids levels in the hair of smokers and non-smokers subjects. Significant differences in the levels of metals and metalloids, $\mathrm{Cr}, \mathrm{Cu}, \mathrm{Fe}, \mathrm{Hg}, \mathrm{Zn}$, and $\mathrm{Pb}$, were observed between smokers and non-smokers subjects in both studied groups (Mann-Whitney $U$ test, $p<0.05)$. However, no significant differences were observed for $\mathrm{Cd}$, As, Ba, Mn, and Sn levels between smokers and non-smokers (Mann-Whitney U test, $p>0.05)$.
Urinary MDA and 8-OHdG in studied groups

Results of MDA and 8-OHdG levels in the urine of studied subjects are provided in Table 3 and Figs. 3 and 4. Significant differences were observed between men and women regarding urinary MDA and 8-OHdG levels (Mann-Whitney U test, $p<0.05$ ). Levels of MDA and 8-OHdG in the urine of smoker subjects were significantly higher than in non-smokers in both groups (Mann-Whitney U test, $p<0.05$ ). The median MDA and 8-OHdG in smokers' urine were 5 and 5.5 times higher than the corresponding values in nonsmokers, respectively. 


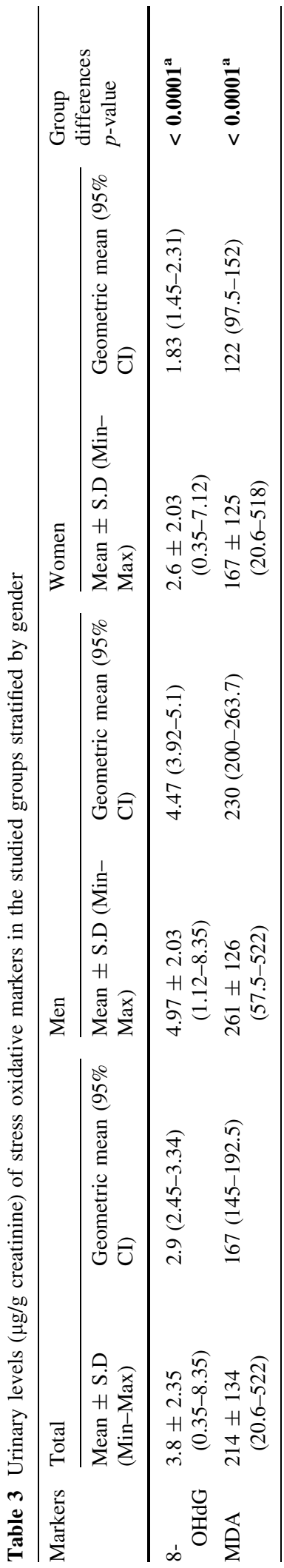

Association between exposure to metals and metalloids and oxidative stress biomarkers

Total metals and metalloids concentrations correlated with the levels of 8-OHdG and MDA were inversely correlated with age (Table S4). The biomarker of oxidative stress (8-OHdG) is correlated with $\mathrm{Al}, \mathrm{B}, \mathrm{Cr}$, $\mathrm{Cu}, \mathrm{Fe}, \mathrm{Hg}, \mathrm{Ni}, \mathrm{Pb}, \mathrm{Si}(p<0.001)$ and $\mathrm{Zn}(p<0.05)$. Likewise, MDA is correlated with $\mathrm{Ag}, \mathrm{Al}, \mathrm{B}, \mathrm{Cd}, \mathrm{Cr}$, $\mathrm{Cu}, \mathrm{Fe}, \mathrm{Hg}, \mathrm{Mn}, \mathrm{Ni}, \mathrm{Pb}, \mathrm{Si}(p<0.01)$ and with As, Ba, $\mathrm{Zn}(p<0.05)$. Age is inversely correlated with As, Si, $\mathrm{Sn}(p<0.01)$ and $\mathrm{Ag}, \mathrm{Al}$ and $\mathrm{Ba}(p<0.05)$.

Table 4 presents the result of regression analysis to evaluate the effects of exposure to metals and metalloids on oxidative stress biomarkers considering sex, age, smoking status, and teeth filling with amalgam as covariates. The levels of Si had significant positive associations with MDA concentration, while Sn showed a negative association ( $p$-value $<0.05$ ). An association between $\mathrm{Cr}, \mathrm{Cu}, \mathrm{Fe}$ with MDA was also suggested $(p<0.10)$.

Regarding the 8-OHdG, higher concentrations were significantly associated with increased levels of $\mathrm{Al}$, $\mathrm{Cu}$, Si $(p<0.05)$ and $\mathrm{Cr}(p<0.1)$, whereas higher levels of $\mathrm{Ba}, \mathrm{Sn}$, and $\mathrm{Zn}$ in hair samples were significantly associated with lower levels of $8-\mathrm{OHdG}$ $(p<0.05)$. In addition, sex was also found to be significantly associated with higher levels of $8-\mathrm{OHdG}$, with males showing higher $8-\mathrm{OHdG}$ concentrations.

Significant associations were observed for cigarette and water-pipe smoking for both MDA and 8-OHdG biomarker levels, with higher biomarker concentrations in smokers.

\section{Discussion}

Concentrations of metals and metalloids in hair samples

The concentrations of metals and metalloids measured in the current study are compared with values reported in the literature from Tehran, a nearby megacity (Rafiee et al., 2020), as well as with concentrations reported elsewhere. The levels of $\mathrm{Ag}, \mathrm{Al}$ and As were very similar to those reported from Tehran subjects (Rafiee et al., 2020), while concentrations of As in this study were higher than those reported in Portugal (Coelho et al., 2014), Greece (Sazakli \& Leotsinidis, 
(a)

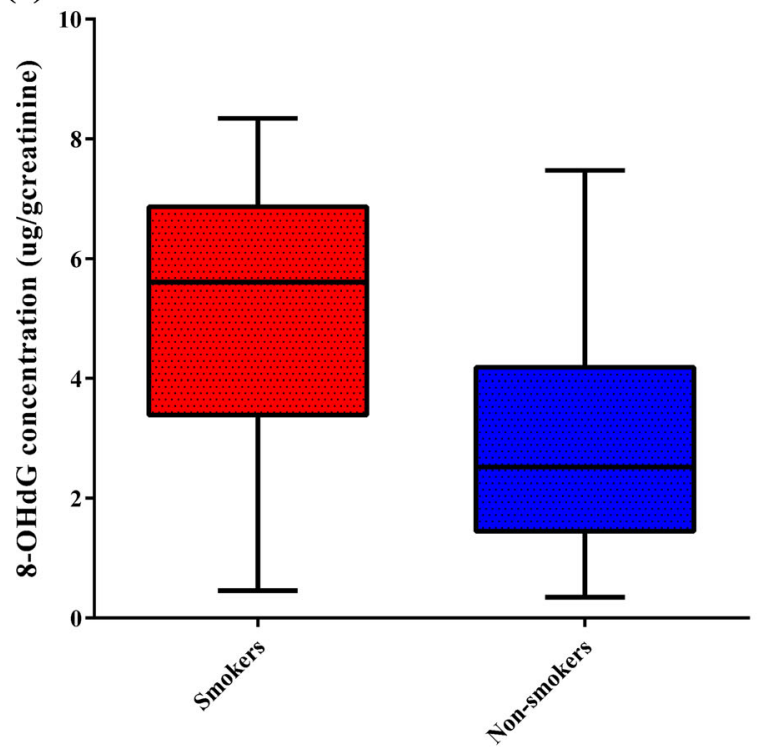

Studied groups (b)

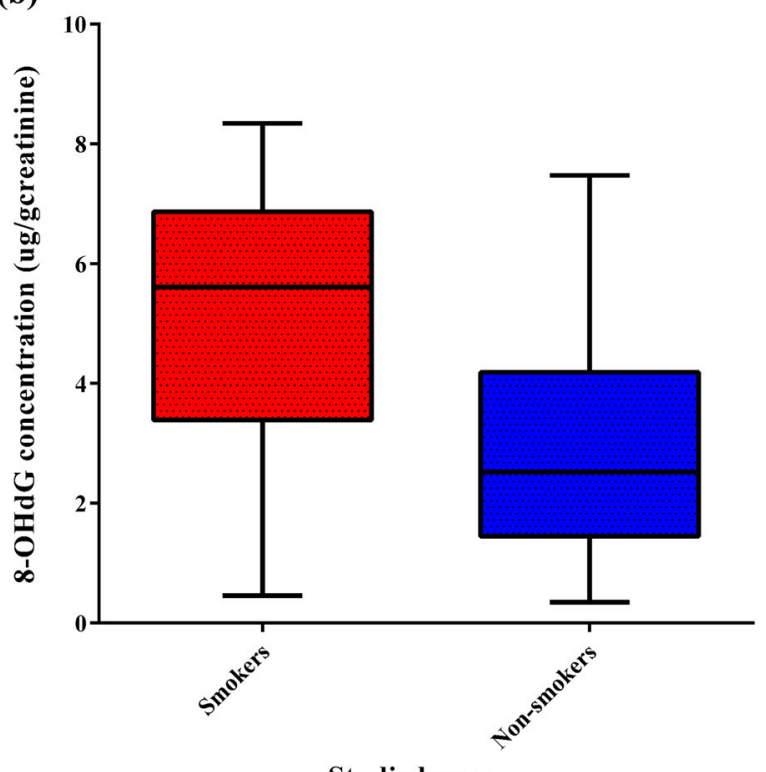

Studied groups

Fig. 3 Comparison of urinary 8-OHdG levels ( $\mu \mathrm{g} / \mathrm{g}$ creatinine) in a men and women and $\mathbf{b}$ smokers and non-smokers

(a)

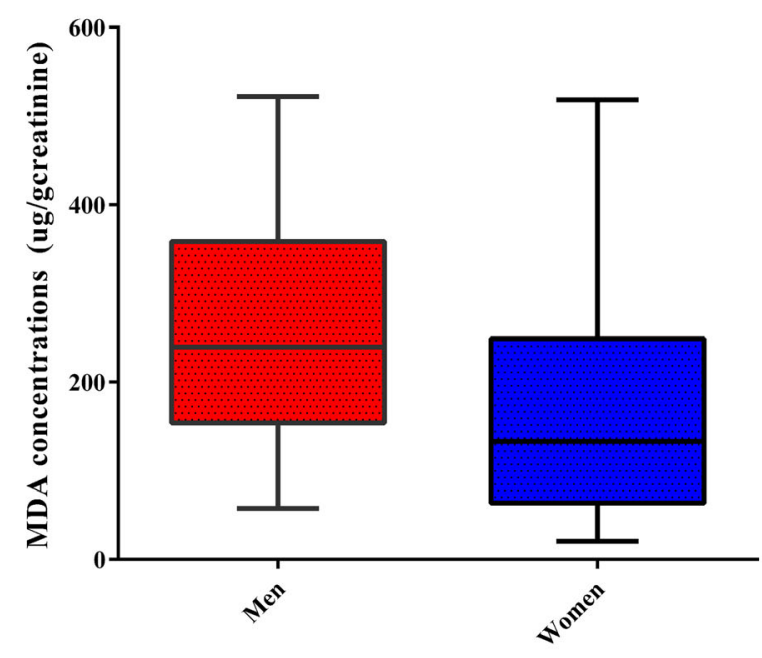

Studied groups (b)

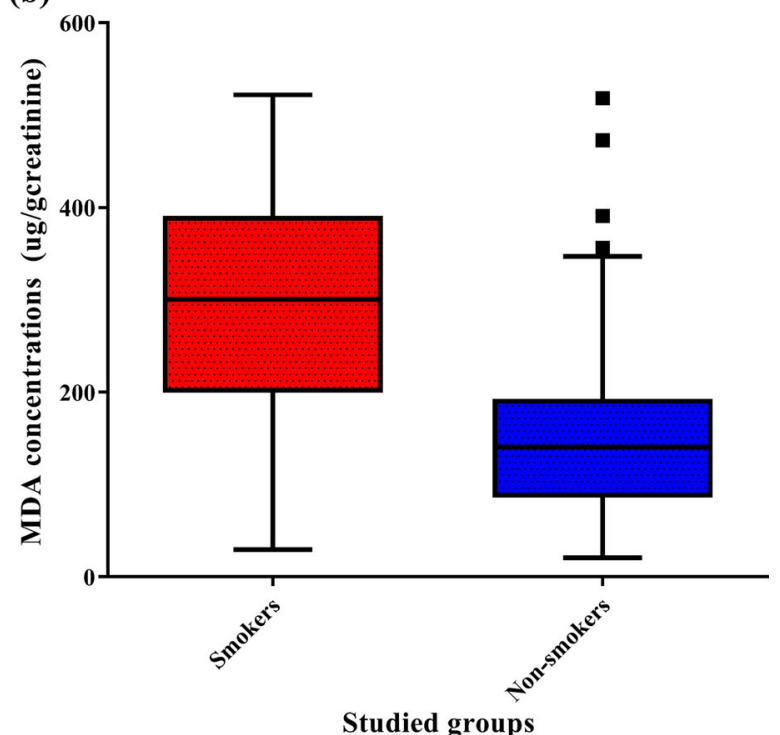

Fig. 4 Comparison of urinary MDA levels ( $\mu \mathrm{g} / \mathrm{g}$ creatinine) in a smokers and non-smokers and $\mathbf{b}$ men and women

2017b) and Italy (Varrica et al., 2014). Thus, exposure to As in Iran appears to be associated with drinking water and dietary intake (Alamdar et al., 2019; Derakhshan et al., 2018; Rahmdel et al., 2018; Torghabeh et al., 2019). Concentrations of $\mathrm{Ni}$ are higher than those reported in Portugal, Greece and
Italy (Coelho et al., 2013; Sazakli \& Leotsinidis, 2017a; Varrica et al., 2014), although lower than concentrations reported in Taiyuan (China) (Zhu et al., 2018). Concentrations of $\mathrm{Hg}$ were higher than those reported in Tehran (Rafiee et al., 2020), China and Spain (Molina-Villalba et al., 2015; Zhu et al., 2018). 
Table 4 Association between oxidative stress biomarkers and chronic exposure to MM and other potential confounders

\begin{tabular}{|c|c|c|c|c|c|c|}
\hline \multirow[t]{2}{*}{ MM Levels and covariates } & \multicolumn{3}{|c|}{ MDA ( $\mu \mathrm{mol} / \mathrm{mol}$ creatinine) } & \multicolumn{3}{|c|}{ 8-OHdG (ng/mmol creatinine) } \\
\hline & Estimate & [95\% Conf. & Interval] & Estimate & [95\% Conf. & Interval] \\
\hline $\mathrm{Ag}$ & 0.193 & -0.250 & 1.547 & 0.079 & -0.805 & 1.607 \\
\hline $\mathrm{Al}$ & 0.171 & -0.008 & 0.069 & 0.226 & 0.010 & 0.112 \\
\hline As & -0.019 & -8.862 & 7.014 & 0.008 & -10.093 & 11.209 \\
\hline $\mathrm{B}$ & -0.066 & -0.015 & 0.008 & -0.081 & -0.021 & 0.008 \\
\hline $\mathrm{Ba}$ & -0.161 & -0.121 & 0.019 & -0.203 & -0.190 & -0.003 \\
\hline $\mathrm{Cd}$ & 0.082 & -0.435 & 0.810 & .038 & -0.704 & 0.967 \\
\hline $\mathrm{Cr}$ & 0.200 & -0.008 & 0.156 & 0.176 & -0.012 & 0.209 \\
\hline $\mathrm{Cu}$ & 0.207 & -0.072 & 1.181 & 0.355 & 0.593 & 2.275 \\
\hline $\mathrm{Fe}$ & 0.275 & -.008 & 0.129 & 0.209 & -0.023 & 0.161 \\
\hline $\mathrm{Hg}$ & 0.051 & -0.087 & 0.151 & 0.090 & -0.074 & 0.245 \\
\hline $\mathrm{Mn}$ & 0.000 & -0.421 & 0.422 & -0.012 & -0.597 & 0.534 \\
\hline $\mathrm{Ni}$ & -0.134 & -1.259 & 0.349 & -0.080 & -1.485 & 0.672 \\
\hline $\mathrm{Pb}$ & -0.124 & -0.492 & 0.131 & -0.052 & -0.532 & 0.305 \\
\hline $\mathrm{Si}$ & 0.322 & 0.032 & 0.341 & 0.358 & 0.106 & 0.520 \\
\hline $\mathrm{Sn}$ & -0.329 & -20.249 & -4.347 & -0.393 & -32.746 & -11.409 \\
\hline $\mathrm{Zn}$ & -0.097 & -0.017 & 0.004 & -0.142 & -0.029 & -0.001 \\
\hline $\operatorname{Sex}(\mathrm{m} / \mathrm{f})$ & -0.100 & -4.573 & 1.715 & -0.212 & -8.790 & -0.353 \\
\hline Age & 0.024 & -0.069 & 0.094 & -0.030 & -0.134 & 0.086 \\
\hline Cigarette smoking $(\mathrm{n} / \mathrm{y})$ & 0.402 & 0.396 & 2.008 & 0.382 & 0.154 & 0.542 \\
\hline Waterpipe smoking (n/y) & 0.302 & 0.117 & 2.859 & 0.281 & 0.182 & 0.908 \\
\hline Teeth filling with amalgam $(\mathrm{y} / \mathrm{n})$ & -0.024 & -3.448 & 2.693 & 0.025 & -3.534 & 4.706 \\
\hline
\end{tabular}

Bold type font in grey cell represent regression coefficients with $p$-value $<0.05$. Italic font represents coefficients with $p$-value $<0.1$. Red font represents positive associations; blue font represents negative associations

Dependent variables: All metals (oids), sex, age, cigarette smoking, waterpipe smoking, and teeth filling with amalgam 
A similar trend was observed for $\mathrm{Zn}$ (Rafiee et al., 2020; Tamburo et al., 2016; Varrica et al., 2014; Zhu et al., 2018), Ni (Rafiee et al., 2020; Zhu et al., 2018) and $\mathrm{Pb}$ (Peña-Fernández et al., 2014; Tamburo et al., 2016; Zhu et al., 2018). Although the concentration of $\mathrm{Pb}$ in the hair in Shiraz are lower than those reported in Tehran (Rafiee et al., 2020). The study in Shiraz reported $\mathrm{Fe}$ levels higher than those previously reported in Tehran (Rafiee et al., 2020) and Sant' Antioco (Italy) (Varrica et al., 2014), although lower than those measured in Taiyuan (China) (Zhu et al., 2018).

Most probably, the routes of exposure to $\mathrm{Pb}$ in Shiraz are similar to those identified in Tehran, mainly being dietary, associated with the use of lead water pipes (Rabin, 2008) and drinking contaminated underground water (because of electronic waste management) ( $\mathrm{Li} \&$ Achal, 2020). Other routes might be inhalation of re-suspended contaminated soil (due to wastewater irrigation) (Qishlaqi et al., 2008) and road dust (e.g. from disk brakes) (Sanderson et al., 2014, 2016). Finally, dermal exposure from the application of hair and cosmetic products (Iwegbue et al., 2016; Salama, 2016) and dietary intake (GalalGorchev, 1993) could also contribute to $\mathrm{Pb}$ exposure in the studied population. $\mathrm{Pb}$ in hair was higher in males than in females (Table 2), consistent with some studies (Ashraf et al., 1995; Rafiee et al., 2020; Sanna et al., 2003; Szynkowska et al., 2015), whereas other studies observed higher $\mathrm{Pb}$ concentrations in females (Peña-Fernández et al., 2014; Tamburo et al., 2016). The elevated concentrations of $\mathrm{Pb}$ in men are most likely because of the use of hair dyes that contain $\mathrm{Pb}$ (Zhu et al., 2018). Exposure to Hg could be attributed to participants having teeth filling with a $\mathrm{Hg}$ amalgam (Rafiee et al., 2020), dietary exposures, e.g. from canned tuna (Zhu et al., 2018), and industrial activities (Zhu et al., 2018). Zn exposure could be attributed to males' use of health supplements (Rafiee et al., 2020). Exposure to $\mathrm{Zn}$ through inhalation of $\mathrm{PM}_{10}$ (Parvizimehr et al., 2020) and re-suspended soil particles (Jahandari, 2020; Keshavarzi et al., 2015; Moghtaderi et al., 2020; Moghtaderi et al., 2019; Torghabeh et al., 2019) cannot be ignored, as well as from dietary intake (Ahmadi \& Ziarati, 2015; Derakhshan et al., 2018; Rahmdel et al., 2018; Sepehri et al., 2018). The intake of $\mathrm{Fe}$ could be attributed to the use of health supplements, inhalation of particulate matter or dietary intake of kebab and grilled sheep's liver rich in iron and popular with males (Rafiee et al., 2020).

\section{Markers of oxidative stress}

The concentrations of MDA and 8-OHdG in the present study (Table 3 ) are higher than concentrations measured in the general population in Ghana (BorteySam et al., 2018). MDA concentrations in Shiraz are also higher than those reported in a rural population in China (Yang et al., 2015). Similarly, 8-OHdG were higher than those reported for university staff in Verona (Italy) (Zanolin et al., 2015) and a Korean population living at different distances from an oil spillage in Korea (Kim et al., 2017). On the other hand, concentrations of $8-\mathrm{OHdG}$ are similar to those reported in school children in Taiwan (Wong et al., 2005), college students in China (Lu et al., 2016) and the general population in Japan (Kimura et al., 2006) and Turkey (Basaran et al., 2020).

Association between metals and metalloids exposure and markers of oxidative stress

No associations are observed between chronic exposure to $\mathrm{Ag}, \mathrm{B}, \mathrm{Mn}$, and any of the two oxidative stress biomarkers studied. No associations were observed either for Ag with MDA in a group of subjects exposed to Ag from local e-waste activities (Li et al., 2020b). A study in a Turkish population neither found an association between B and 8-OHdG (Basaran et al., 2020). Results of our study are consistent with results reported in a study in a pregnant population in Bangladesh, in which chronic Mn exposure was not associated with 8-OHdG (Engstrom et al., 2010).

This study shows that chronic $\mathrm{Fe}$ exposure is associated with MDA but not with 8-OHdG. A randomized controlled trial study supplementing $\mathrm{Fe}$ in lactating mothers found neither an association between Fe exposure and 8-OHdG (Jorgensen et al., 2017). On the other hand, a study conducted on asthmatic children found a significant association between Fe and MDA concentrations (Kocyigit et al., 2004).

Chronic $\mathrm{Al}$ exposure was associated with increased levels of 8-OHdG, but not MDA, which is consistent with results reported in a Japanese study for short-term $\mathrm{Al}$ exposure, although in their case, the association was suggestive $(p>0.10)$ (Kimura et al., 2006). On 
the other hand, the Japanese study shows a positive association for short-term As exposure with 8-OHdG, consistent with He et al. (2020) and other study of chronic As exposure in pregnant women in Bangladesh (Engstrom et al., 2010), and at odds with our observations. In contrast, a study conducted among school children in Taiwan, neither found an association between short-term exposure and 8-OHdG (Wong et al., 2005), consistent with our observations.

This study shows an inverse association between chronic Ba exposure and $8-\mathrm{OHdG}$, but not for MDA. Domingo-Relloso et al., (2019) did not find any association with MDA either, but found a significant positive association between short-term Ba exposure and 8-OHdG (Domingo-Relloso et al., 2019).

Chronic Cd exposure did not show any association with MDA or 8-OHdG in this study. While DomingoRelloso et al., (2019) did not observe any association for 8-OHdG either, they report an association with MDA for short-term Cd exposure (Domingo-Relloso et al., 2019). On the other hand, a positive association was reported between short-term $\mathrm{Cd}$ exposure and 8-OHdG levels in a study in Wuhan (He et al., 2020), Korea (Eom et al., 2017) and chronic exposure in rural Bangladesh (Engstrom et al., 2010).

This study shows a suggestive $(p<0.10)$ association between chronic $\mathrm{Cr}$ exposure and urinary MDA and $8-\mathrm{OHdG}$ concentrations. This is consistent with observations for short-term $\mathrm{Cr}$ exposure and 8-OHdG in Taiwanese school children (Wong et al., 2005) and the Japanese general population (Kimura et al., 2006), which show a positive association $(p<0.05)$. On the other hand, no associations were reported for shortterm $\mathrm{Cr}$ exposure with MDA or $8-\mathrm{OHdG}$ in the Spanish Hortega study (Domingo-Relloso et al., 2019).

Chronic $\mathrm{Cu}$ exposure shows an association with $8-\mathrm{OHdG}$, while the association is only suggestive $(p>0.10)$ for MDA. In contrast, no associations were reported between short-term $\mathrm{Cu}$ exposure and 8-OHdG nor MDA in the Spanish Hortega study (Domingo-Relloso et al., 2019), nor was it found for $8-\mathrm{OHdG}$ in a Japanese population study (Kimura et al., 2006).

No association was reported between chronic $\mathrm{Hg}$ or $\mathrm{Ni}$ exposure and MDA or 8-OHdG levels (Table 4), consistent with results for short-term exposure in a Japanese study, although in their case, the association with $\mathrm{Ni}$ was suggestive $(p>0.10)$ (Kimura et al., 2006).

He et al. (2020) showed a significant dose-dependent relationship between urinary $\mathrm{Pb}$ with 8 -OHdG. In this study, while $\mathrm{Pb}$ concentrations in hair show a significant correlation with $8-\mathrm{OHdG}$ (Table S1); results of the regression model that consider the effect of other covariates, do not show any dose-dependent association (Table 4). Our results are consistent with observations in a Japanese study (Kimura et al., 2006).

This study shows a positive association between chronic Si exposure and MDA and 8-OHdG concentrations. On the other hand, chronic Sn exposure is inversely associated with MDA and 8-OHdG concentrations, which is at odds with a study assessing the effect of metals on AHDH in children, which reported positive correlations instead (Li et al., 2020a).

An inverse association between chronic $\mathrm{Zn}$ exposure and 8-OHdG, but not with MDA, is at odds with the Spanish Hortega study results, which report positive associations between short-term $\mathrm{Zn}$ exposure and both MDA and 8-OHdG (Domingo-Relloso et al., 2019), while no associations were reported in a Japanese population study (Kimura et al., 2006).

The differences observed between observations of the current study with the literature might be related to the fact that different matrices were used to characterize metal exposure (e.g. hair vs urine or blood); to the fact that our study captures chronic exposure, while the other studies reflect short-term exposure. For example, As, $\mathrm{Cr}$, Ni tend to be excreted quickly from the body through urine. Therefore, urinary concentrations represent short-term exposure (Kuo et al., 2003). It can also be related to the covariates used to adjust each model, which although most of them try to capture socioeconomic factors, the variables themselves might vary among the different studies presented. Finally, although these studies examine the effect of exposure to metals on oxidative stress biomarkers, no information on other environmental exposures is considered in these studies, which might be (at least partially) driving the associations observed. All these factors could be important determinants explaining the differences observed.

Age has not been identified as an important covariate in the regression analysis in this study (Table 4), despite showing an inverse correlation in the Pearson analysis (Table S1). In the study by Bortey-Sam et al. (2018), only Co correlated 
statistically with age, but age was not identified as a significant covariate for any of the other metals analyzed in the Ghanaian study (Bortey-Sam et al., 2018), consistent with our results. The link between the aging factor and 8 -OHdG has been debatable (Miwa et al., 2004; Toraason et al., 2003; Wong et al., 2005).

Sex has been identified as a significant covariate for the 8-OHdG analysis only, but not for the MDA. Differential sex effects have been reported when comparing both oxidative biomarker concentrations in the present study (Table 3). The effect of sex on oxidative stress levels warrants further investigation, as conflicting results are reported in the various studies examined (Bortey-Sam et al., 2018; Eom et al., 2017; Kimura et al., 2006; Wong et al., 2005; Zanolin et al., 2015). This might indicate that the sex differences observed in this study might not truly reflect sex inherent differences but could be attributed to other factors, e.g. socioeconomic or exposures to other environmental factors not considered in the present study.

Figures 3 and 4 show that smokers have higher levels of oxidative stress biomarkers $8-\mathrm{OHdG}$ and MDA, respectively. Consistent with this observation, the regression analysis highlights smoking cigarettes and water-pipe as significant contributing factors to increased ROS damage, with increased levels of MDA and 8-OHdG (Table 4). This is consistent with results in several studies that report significantly higher concentrations of these ROS biomarkers in smokers (Tagesson et al., 1996; Yang et al., 2015; Zanolin et al., 2015). In contrast, no smoking effect was observed in 8-OHdG concentrations collected from a sample of general population in Japan (Kimura et al., 2006). The complexity of cigarette type, quality of tobacco and compounds produced during passive smoking might explain the difference across studies.

Amalgam filling has not been identified as a significant factor explaining elevated MDA or 8-OHdG concentrations in the present study (Table 4). This is consistent with the study by de Almeida Lopes et al., (2017), in which the correlation between blood levels of $\mathrm{Pb}, \mathrm{Cd}$ and $\mathrm{Hg}$ was not statistically significant with MDA in environmentally exposed Brazilian adults, even though the $\mathrm{Hg}$ levels were higher in subjects having amalgam fillings.
Limitations and strengths

Other factors that might be associated with increase oxidative stress might have not been captured in the current study design. For instance, urinary 8-OHdG levels are susceptible to environmental pollutant exposure, such as diesel exhaust emissions, electronic waste dismantling (Wang et al., 2010), and cooking fumes (Ke et al., 2009). Such factors might also contribute to the high oxidative stress biomarker concentrations obtained in this study. Another limitation of our study was using spot urine samples to assess the association between ROS markers with metals and metalloids. Ideally, 24-h pooled or fasting urine samples should be employed to assess biomarkers of oxidative stress, especially when including smokers in the population under study (Zanolin et al., 2015). However, Miwa et al. (2004) studied the diurnal variability of $8-\mathrm{OHdG}$ and concluded that a morning spot urine sample could be used to measure 8-OHdG instead of inconvenient 24-h sampling, despite the inherent variability in the biomarker excretion across the day (Miwa et al., 2004).

This study reports chronic exposure to metals in an urban population from a middle-income country in the Middle East, providing valuable information about metal exposures for a population where such evidence is scarce. In addition, it has also analyzed levels of two different oxidative stress biomarkers and analyzed the associations between chronic metal exposures and oxidative stress. Most of the available studies focus on short-term exposures, while information on such associations on chronic exposures is very limited, even more from low- and middle-income countries in the Middle East or elsewhere. Therefore, this study provides valuable evidence to evaluate chronic exposure to metals in this region of the world and their effects on oxidative stress.

\section{Conclusion}

The carcinogenic effects due to chronic exposure to metals is not well characterized. However, it is generally assumed that the concept of additivity applies when the exposure is associated with lowlevel chemical mixtures (Hartwig \& Schwerdtle, 2002). This study shows that urban residents of Shiraz, one of the main urban centers in the Middle East, are chronically exposed to elevated concentrations of As, 
$\mathrm{Ni}, \mathrm{Hg}$ and $\mathrm{Pb}$. Concentrations of MDA are lower than concentrations reported in other studies, while concentrations of $8-\mathrm{OHdG}$ are intermediate. Results of regression analyses assessing the association between urinary ROS markers with metals and metalloids, adjusted for other confounders, highlight that $\mathrm{Al}, \mathrm{Cu}$, $\mathrm{Si}$ and $\mathrm{Sn}$ are associated with $8-\mathrm{OHdG}$ concentrations, while $\mathrm{Cr}$ suggests an association with both MDA and 8-OHdG. In addition, smoking cigarettes and waterpipe is considered a significant risk factor increasing the concentrations of both ROS biomarkers (MDA and 8-OHdG).

Given that several metals have been significantly associated with ROS biomarkers and considering that ROS might be a significant factor in the etiology of many health diseases, further research of the health effect of metal in dose-effect relationships of environmentally exposed subjects should be implemented.

Authors' contributions AR: Conceptualization, Methodology development, Formal Analysis, Writing-Original draft preparation, Reviewing and Editing. JMD-S: WritingReviewing and Editing. NJA: Writing. HA: Data curation. $\mathrm{MH}$ : Funding acquisition and Project administration.

Funding The present study was financially supported by the Shiraz University of Medical Sciences (grant no.17569). Authors thank all the subjects who took part in this study.

\section{Declarations}

Conflict of Interest Authors declare they do not have any competing financial interests in relation to this study.

Ethics approval The Ethical Committee approved the present study at the Shiraz University of Medical Sciences (IR.SUMS.REC.1398.320).

Consent to participate All subjects were informed about study's objectives and gave written consent to participate in this study.

Data availability Authors Not applicable.

Code availability Not applicable.

\section{References}

Ahmadi, A., \& Ziarati, P. (2015). Chemical composition profile of canned and frozen sweet corn (Zea mays L.) in Iran. Oriental Journal of Chemistry, 31, 1065-1070.
Al Hanai, A. H., Antkiewicz, D. S., Hemming, J. D., Shafer, M. M., Lai, A. M., Arhami, M., Hosseini, V., \& Schauer, J. J. (2019). Seasonal variations in the oxidative stress and inflammatory potential of PM2.5 in Tehran using an alveolar macrophage model; The role of chemical composition and sources. Environment International, 123, 417-427.

Alamdar, R., Kumar, V., Moghtaderi, T., \& Naghibi, S. J. (2019). Groundwater quality evaluation of Shiraz City, Iran using multivariate and geostatistical techniques. SN Applied Sciences, 1(11), 1-16.

Alimonti, A., Ristori, G., Giubilei, F., Stazi, M. A., Pino, A., Visconti, A., Brescianini, S., Monti, M. S., Forte, G., Stanzione, P., \& Bocca, B. (2007). Serum chemical elements and oxidative status in Alzheimer's disease, Parkinson disease and multiple sclerosis. Neurotoxicology, $28,450-456$.

Almeida Lopes, A. C. B., Urbano, M. R., de Souza-Nogueira, A., Oliveira-Paula, G. H., Michelin, A. P., de Fátima, M. H. C., Camargo, A. E., Peixe, T. S., Cabrera, M. A., \& Paoliello, M. M. (2017). Association of lead, cadmium and mercury with paraoxonase 1 activity and malondialdehyde in a general population in Southern Brazil. Environmental Research, 156, 674-682.

Amaral, A. F. S., Arruda, M., Cabral, S., \& Rodrigues, A. S. (2008). Essential and non-essential trace metals in scalp hair of men chronically exposed to volcanogenic metals in the Azores, Portugal. Environment International, 34, 1104-1108.

Amato, F., Cassee, F. R., van der Gon, H. A., Gehrig, R., Gustafsson, M., Hafner, W., Harrison, R. M., Jozwicka, M., Kelly, F. J., Moreno, T., \& Prevot, A. S. (2014). Urban air quality: The challenge of traffic non-exhaust emissions. Journal of Hazardous Materials, 275, 31-36.

Amato, F., Favez, O., Pandolfi, M., Alastuey, A., Querol, X., Moukhtar, S., Bruge, B., Verlhac, S., Orza, J. A., Bonnaire, N., \& Le Priol, T. (2016). Traffic induced particle resuspension in Paris: Emission factors and source contributions. Atmospheric Environment, 129, 114-124.

Ashraf, W., Jaffar, M., Anwer, K., \& Ehsan, U. (1995). Age- and sex-based comparative distribution of selected metals in the scalp hair of an urban population from two cities in Pakistan. Environmental Pollution, 87, 61-64.

ATSDR. (2013). Summary Data for 2013 Priority List of Hazardous Substances. Department of Health and Human Services, Public Health Service Atlanta.

Barbieri, F., Cournil, A., Sarkis, J. E. S., Bénéfice, E., \& Gardon, J. (2011). Hair trace elements concentration to describe polymetallic mining waste exposure in Bolivian Altiplano. Biological Trace Element Research, 139(1), 10-23.

Başaran, N., Duydu, Y., Bacanlı, M., Anlar, H. G., Dilsiz, S. A., Üstündağ, A., Yalçın, C. Ö., Schwerdtle, T., \& Bolt, H. M. (2020). Evaluation of oxidative stress and immune parameters of boron exposed males and females. Food and Chemical Toxicology, 142, 6.

Boogaard, H., Kos, G. P., Weijers, E. P., Janssen, N. A., Fischer, P. H., van der Zee, S. C., de Hartog, J. J., \& Hoek, G. (2011). Contrast in air pollution components between major streets and background locations: Particulate matter mass, black carbon, elemental composition, nitrogen oxide 
and ultrafine particle number. Atmospheric Environment, $45,650-658$.

Bortey-Sam, N., Ikenaka, Y., Akoto, O., Nakayama, S. M., Asante, K. A., Baidoo, E., Obirikorang, C., Mizukawa, H., \& Ishizuka, M. (2018). Association between human exposure to heavy metals/metalloid and occurrences of respiratory diseases, lipid peroxidation and DNA damage in Kumasi, Ghana. Environmental Pollution, 235, 163-170.

Bowler, R. M., Nakagawa, S., Drezgic, M., Roels, H. A., Park, R. M., Diamond, E., Mergler, D., Bouchard, M., Bowler, R. P., \& Koller, W. (2007). Sequelae of fume exposure in confined space welding: A neurological and neuropsychological case series. Neurotoxicology, 28, 298-311.

Butler, A. R. (1975). The Jaffe reaction. Identification of the coloured species. Clinica Chimica Acta, 59, 227-232.

Carneiro, M. F. H., Grotto, D., Batista, B. L., Rhoden, C. R., \& Barbosa, J. F. (2011). Background values for essential and toxic elements in Children's nails and correlation with hair levels. Biological Trace Element Research, 144, 339-350.

Chatziargyriou, V., \& Dailianis, S. (2010). The role of seleniumdependent glutathione peroxidase (Se-GPx) against oxidative and genotoxic effects of mercury in haemocytes of mussel Mytilus galloprovincialis (Lmk.). Toxicology in Vitro, 24, 1363-1372.

Chen, P., Miah, M., \& Aschner, M. (2016). Metals and neurodegeneration. F1000Research, 5, 366.

Coelho, P., Costa, S., Costa, C., Silva, S., Walter, A., Ranville, J., Pastorinho, M. R., Harrington, C., Taylor, A., Dall'Armi, V., \& Zoffoli, R. (2013). Biomonitoring of several toxic metal(loid)s in different biological matrices from environmentally and occupationally exposed populations from Panasqueira mine area, Portugal. 36.

Coelho, P., Costa, S., Costa, C., Silva, S., Walter, A., Ranville, J., Pastorinho, M. R., Harrington, C., Taylor, A., Dall'Armi, V., \& Zoffoli, R. (2014). Biomonitoring of several toxic metal(loid)s in different biological matrices from environmentally and occupationally exposed populations from Panasqueira mine area, Portugal. Environmental Geochemistry and Health, 36, 255-269.

Denier van der Gon, H. A., Gerlofs-Nijland, M. E., Gehrig, R., Gustafsson, M., Janssen, N., Harrison, R. M., Hulskotte, J., Johansson, C., Jozwicka, M., Keuken, M., \& Krijgsheld, K. (2013). The policy relevance of wear emissions from road transport, now and in the future-An international workshop report and consensus statement. Journal of the Air \& Waste Management Association, 63, 136-149.

Derakhshan, Z., Mahvi, A. H., Faramarzian, M., Dehghani, M., Salari, M., Fakhri, Y., Afsharnia, M., Hosseini, M. S., Marzban, A., \& Taghavi, M. (2018). Data on heavy metal concentration in common carp fish consumed in Shiraz, Iran. Data in Brief, 21, 1890-1894.

Domingo-Relloso, A., Grau-Perez, M., Galan-Chilet, I., Garrido-Martinez, M. J., Tormos, C., Navas-Acien, A., Gomez-Ariza, J. L., Monzo-Beltran, L., Saez-Tormo, G., Garcia-Barrera, T., \& Laita, A. D. (2019). Urinary metals and metal mixtures and oxidative stress biomarkers in an adult population from Spain: The Hortega Study. Environment International, 123, 171-180.

Drobyshev, E. J., Solovyev, N. D., Ivanenko, N. B., Kombarova, M. Y., \& Ganeev, A. A. (2017). Trace element biomonitoring in hair of school children from a polluted area by sector field inductively coupled plasma mass spectrometry. Journal of Trace Elements in Medicine and Biology: Organ of the Society for Minerals and Trace Elements (GMS), 39, 14-20.

Engström, K. S., Vahter, M., Johansson, G., Lindh, C. H., Teichert, F., Singh, R., Kippler, M., Nermell, B., Raqib, R., Strömberg, U., \& Broberg, K. (2010). Chronic exposure to cadmium and arsenic strongly influences concentrations of 8-oxo-7,8-dihydro-2'-deoxyguanosine in urine. Free Radical Biology and Medicine, 48, 1211-1217.

Eom, S. Y., Seo, M. N., Lee, Y. S., Park, K. S., Hong, Y. S., Sohn, S. J., Kim, Y. D., Choi, B. S., Lim, J. A., Kwon, H. J., Kim, H. (2017). Low-level environmental cadmium exposure induces kidney tubule damage in the general population of Korean Adults. Archives of Environmental Contamination and Toxicology, 73, 401-409.

Eqani, S., Tanveer, Z. I., Qiaoqiao, C., Cincinelli, A., Saqib, Z., Mulla, S. I., Ali, N., Katsoyiannis, I. A., Shafqat, M. N., \& Shen, H. (2018). Occurrence of selected elements (Ti, Sr, $\mathrm{Ba}, \mathrm{V}, \mathrm{Ga}, \mathrm{Sn}, \mathrm{Tl}$, and $\mathrm{Sb}$ ) in deposited dust and human hair samples: Implications for human health in Pakistan. Environmental Science and Pollution Research, 25, 12234-12245.

Fábelová, L., Vandentorren, S., Vuillermoz, C., Garnier, R., Lioret, S., \& Botton, J. (2018). Hair concentration of trace elements and growth in homeless children aged <6years: Results from the ENFAMS study. Environment International, 114, 318-325.

Farmand, F., Ehdaie, A., Roberts, C. K., \& Sindhu, R. K. (2005). Lead-induced dysregulation of superoxide dismutases, catalase, glutathione peroxidase, and guanylate cyclase. Environmental Research, 98, 33-39.

Galal-Gorchev, H. (1993). Dietary intake, levels in food and estimated intake of lead, cadmium, and mercury. Food Additives \& Contaminants, 10, 115-128.

Gietl, J. K., Lawrence, R., Thorpe, A. J., \& Harrison, R. M. (2010). Identification of brake wear particles and derivation of a quantitative tracer for brake dust at a major road. Atmospheric Environment, 44, 141-146.

Gil F, Hernandez Jerez A. Significance of Biochemical Markers in Applied Toxicology. 2, 2009.

Halliwell, B., \& Cross, C. E. (1994). Oxygen-derived species: Their relation to human disease and environmental stress. Environmental Health Perspectives, 102, 5-12.

Harrison, R. M., Yin, J., Mark, D., Stedman, J., Appleby, R. S., Booker, J., Moorcroft, S. (2001). Studies of the coarse particle $(2.5-10 \mu \mathrm{m})$ component in UK urban atmospheres. Atmospheric Environment, 35, 3667-3679.

Hartwig, A., \& Schwerdtle, T. (2002). Interactions by carcinogenic metal compounds with DNA repair processes: Toxicological implications. Toxicology Letters, 127, 47-54.

He, Y., Zou, L., Luo, W., Yi, Z., Yang, P., Yu, S., Liu, N., Ji, J., Guo, Y., Liu, P., \& He, X. (2020). Heavy metal exposure, oxidative stress and semen quality: Exploring associations and mediation effects in reproductive-aged men. Chemosphere, 244, 125498.

Hoseini, M., Nabizadeh, R., Delgado-Saborit, J. M., Rafiee, A., Yaghmaeian, K., Parmy, S., Faridi, S., Hassanvand, M. S., Yunesian, M., \& Naddafi, K. (2018). Environmental and lifestyle factors affecting exposure to polycyclic aromatic 
hydrocarbons in the general population in a Middle Eastern area. Environmental Pollution, 240, 781-792.

Iwegbue, C. M. A., Emakunu, O. S., Obi, G., Nwajei, G. E., \& Martincigh, B. S. (2016). Evaluation of human exposure to metals from some commonly used hair care products in Nigeria. Toxicology Reports, 3, 796-803.

Jahandari, A. (2020). Pollution status and human health risk assessments of selected heavy metals in urban dust of 16 cities in Iran. Environmental Science and Pollution Research, 27, 23094-23107.

Jorgensen, J. M., Yang, Z. Y., Lonnerdal, B., Chantry, C. J., \& Dewey, K. G. (2017). Effect of iron supplementation during lactation on maternal iron status and oxidative stress: A randomized controlled trial. Maternal and Child Nutrition, 13,11 .

Ke, Y., Cheng, J., Zhang, Z., Zhang, R., Zhang, Z., Shuai, Z., $\mathrm{Wu}, \mathrm{T}$. (2009). Increased levels of oxidative DNA damage attributable to cooking-oil fumes exposure among cooks. Inhalation Toxicology, 21, 682-687.

Keshavarzi, B., Tazarvi, Z., Rajabzadeh, M. A., \& Najmeddin, A. (2015). Chemical speciation, human health risk assessment and pollution level of selected heavy metals in urban street dust of Shiraz, Iran. Atmospheric Environment, $119,1-10$

Keuken, M. P., Moerman, M., Voogt, M., Blom, M., Weijers, E. P., Röckmann, T., \& Dusek, U. (2013). Source contributions to PM2.5 and PM10 at an urban background and a street location. Atmospheric Environment, 71, 26-35.

Kim, J. A., Noh, S. R., Cheong, H. K., Ha, M., Eom, S. Y., Kim, H., Park, M. S., Chu, Y., Lee, S. H., \& Choi, K. (2017). Urinary oxidative stress biomarkers among local residents measured 6 years after the Hebei Spirit oil spill. Science of the Total Environment, 580, 946-952.

Kimura, S., Yamauchi, H., Hibino, Y., Iwamoto, M., Sera, K., \& Ogino, K. (2006). Evaluation of urmiary 8-hydroxydeoxyguanine in healthy Japanese people. Basic \& Clinical Pharmacology \& Toxicology, 98, 496-502.

Kocyigit, A., Armutcu, F., Gurel, A., \& Ermis, B. (2004). Alterations in plasma essential trace elements selenium, manganese, zinc, copper, and iron concentrations and the possible role of these elements on oxidative status in patients with childhood asthma. Biological Trace Element Research, 97, 31-41.

Kuo, H., Chang, S., Wu, K., \& Wu, F. (2003). Chromium (VI) induced oxidative damage to DNA: Increase of urinary 8-hydroxydeoxyguanosine concentrations (8-OHdG) among electroplating workers. Occupational and Environmental Medicine, 60, 590-594.

Kwak, J.-H., Kim, H., Lee, J., \& Lee, S. (2013). Characterization of non-exhaust coarse and fine particles from on-road driving and laboratory measurements. Science of the Total Environment, 458-460, 273-282.

Lawrence, S., Sokhi, R., Ravindra, K., Mao, H., Prain, H. D., \& Bull, I. D. (2013). Source apportionment of traffic emissions of particulate matter using tunnel measurements. Atmospheric Environment, 77, 548-557.

Lenschow, P., Abraham, H. J., Kutzner, K., Lutz, M., Preuß, J. D., \& Reichenbächer, W. (2001). Some ideas about the sources of PM10. Atmospheric Environment, 35, S23-S33.

Li, J., Cen, D., Huang, D., Li, X., Xu, J., Fu, S., Cai, R., Wu, X., Tang, M., Sun, Y., \& Zhang, J. (2014). Detection and analysis of 12 heavy metals in blood and hair sample from a general population of Pearl River Delta Area. Cell Biochemistry and Biophysics, 70, 1663-1669.

Li, W., \& Achal, V. (2020). Environmental and health impacts due to e-waste disposal in China-A review. Science of the Total Environment, 737, 139745.

Li, Y., Cha, C., Lv, X., Liu, J., He, J., Pang, Q., Meng, L., Kuang, H., \& Fan, R. (2020a). Association between 10 urinary heavy metal exposure and attention deficit hyperactivity disorder for children. Environmental Science and Pollution Research, 27, 31233-31242.

Li, Z., Li, X., Qian, Y., Guo, C., Wang, Z., \& Wei, Y. (2020b). The sustaining effects of e-waste-related metal exposure on hypothalamus-pituitary-adrenal axis reactivity and oxidative stress. Science of the Total Environment, 739, 139964.

Lin, C.-C. (2016). A review of the impact of fireworks on particulate matter in ambient air. Journal of the Air \& Waste Management Association, 66, 1171-1182.

Liu, Y., Wang, H., Li, X., \& Li, J. (2015). Heavy Metal Contamination of Agricultural Soils in Taiyuan, China. Pedosphere, 25, 901-909.

Lu, S. Y., Ren, L., Fang, J. Z., Ji, J. J., Liu, G. H., Zhang, J. Q., Zhang, H., Luo, R., Lin, K., \& Fan, R. (2016). Trace elements are associated with urinary 8-hydroxy-2'-deoxyguanosine level: A case study of college students in Guangzhou, China. Environmental Science and Pollution Research, 23, 8484-8491.

Luo, R., Zhuo, X., \& Ma, D. (2014). Determination of 33 elements in scalp hair samples from inhabitants of a mountain village of Tonglu city, China. $104 \mathrm{C}$.

Mirzaei, S., Hashemi, H., \& Hoseini, M. (2018). Concentration and potential source identification of trace elements in wet atmospheric precipitation of Shiraz. Iran. Journal of Environmental Health Science and Engineering, 16, 229-237.

Miwa, M., Matsumaru, H., Akimoto, Y., Naito, S., \& Ochi, H. (2004). Quantitative determination of urinary 8-hydroxy$2^{\prime}$-deoxyguanosine level in healthy Japanese volunteers. BioFactors, 22, 249-253.

Moghtaderi, T., Alamdar, R., Rodriguez-Seijo, A., Naghibi, S. J., \& Kumar, V. (2020). Ecological risk assessment and source apportionment of heavy metal contamination in urban soils in Shiraz, Southwest Iran. Arabian Journal of Geosciences, 13.

Moghtaderi, T., Aminiyan, M. M., Alamdar, R., \& Moghtaderi, M. (2019). Index-based evaluation of pollution characteristics and health risk of potentially toxic metals in schools dust of Shiraz megacity, SW Iran. Human and Ecological Risk Assessment, 25, 410-437.

Molina-Villalba, I., Lacasaña, M., Rodríguez-Barranco, M., Hernández, A. F., Gonzalez-Alzaga, B., Aguilar-Garduño, C., Gil, F. (2015). Biomonitoring of arsenic, cadmium, lead, manganese and mercury in urine and hair of children living near mining and industrial areas. Chemosphere, 124, 83-91.

Nnorom, I. C., Igwe, J. C., \& Ejimone, J. C. (2005). Multielement analyses of human scalp hair samples from three distant towns in southeastern Nigeria. African Journal of Biotechnology, 4, 1124-1127.

Pan, Y., \& Li, H. (2015). Trace elements in scalp hair from potentially exposed individuals in the vicinity of the Bayan 
Obo mine in Baotou. China. Environmental Toxicology and Pharmacology, 40, 678-685.

Parvizimehr, A., Baghani, A. N., Hoseini, M., Sorooshian, A., Cuevas-Robles, A., Fararouei, M., Dehghani, M., Delikhoon, M., Barkhordari, A., Shahsavani, S., \& Badeenezhad, A. On the nature of heavy metals in PM10 for an urban desert city in the Middle East: Shiraz, Iran. Microchemical Journal, 154: 104596.

Peña-Fernández, A., Lobo-Bedmar, M. C., \& González-Muñoz, M. J. (2014). Monitoring lead in hair of children and adolescents of Alcalá de Henares, Spain. A study by gender and residential areas. Environment International, 72, $170-175$.

Qishlaqi, A., Moore, F., \& Forghani, G. (2008). Impact of untreated wastewater irrigation on soils and crops in Shiraz suburban area, SW Iran. Environmental Monitoring and Assessment, 141, 257-273.

Querol, X., Alastuey, A., Ruiz, C. R., Artiñano, B., Hansson, H. C., Harrison, R. M., Buringh, E. T., Ten Brink, H. M., Lutz, M., Bruckmann, P., \& Straehl, P. (2004). Speciation and origin of PM10 and PM2.5 in selected European cities. Atmospheric Environment, 38, 6547-6555.

Querol, X., Viana, M., Alastuey, A., Amato, F., Moreno, T., Castillo, S., Pey, J., De la Rosa, J., De La Campa, A. S., Artínano, B., \& Salvador P. (2007). Source origin of trace elements in PM from regional background, urban and industrial sites of Spain. Atmospheric Environment, 41, 7219-7231.

Rabin, R. (2008). The lead industry and lead water pipes "A Modest Campaign." American Journal of Public Health, 98, 1584-1592.

Rafiee, A., Delgado-Saborit, J. M., Gordi, E., Quémerais, B., Kazemi Moghadam, V., Lu, W., Hashemi, F., \& Hoseini, M. (2018a). Use of urinary biomarkers to characterize occupational exposure to BTEX in healthcare waste autoclave operators. Science of the Total Environment, 631-632, 857-865.

Rafiee, A., Delgado-Saborit, J. M., Sly, P. D., Amiri, H., \& Hoseini, M. (2019). Lifestyle and occupational factors affecting exposure to BTEX in municipal solid waste composting facility workers. Science of the Total Environment, 656, 540-546.

Rafiee, A., Delgado-Saborit, J. M., Sly, P. D., Quémerais, B., Hashemi, F., Akbari, S., \& Hoseini, M. (2020). Environmental chronic exposure to metals and effects on attention and executive function in the general population. Science of the Total Environment, 705, 135911.

Rafiee, A., Gordi, E., Lu, W., Miyata, Y., Shabani, H., Mortezazadeh, S., \& Hoseini, M. (2018b). The impact of various festivals and events on recycling potential of municipal solid waste in Tehran, Iran. Journal of Cleaner Production, 183, 77-86.

Rafiee, A., Yaghmaeian, K., Hoseini, M., Parmy, S., Mahvi, A., Yunesian, M., Khaefi, M., \& Nabizadeh, R. (2016). Assessment and selection of the best treatment alternative for infectious waste by modified Sustainability Assessment of Technologies methodology. Journal of Environmental Health Science and Engineering, 14, 1-14.

Rahmdel, S., Rezaei, M., Ekhlasi, J., Zarei, S. H., Akhlaghi, M., Abdollahzadeh, S. M., Sefidkar, R., \& Mazloomi, S. M. Heavy metals $(\mathrm{Pb}, \mathrm{Cd}, \mathrm{Cu}, \mathrm{Zn}, \mathrm{Ni}, \mathrm{Co})$ in leafy vegetables collected from production sites: Their potential health risk to the general population in Shiraz, Iran. Environmental Monitoring and Assessment, 190.

Richmond-Bryant, J., Meng, Q., Davis, A., Cohen, J., Lu, S. E., Svendsgaard, D., Brown, J. S., Tuttle, L., Hubbard, H., Rice, J., \& Kirrane, E. (2014). The influence of declining air lead levels on blood lead-air lead slope factors in children. Environmental Health Perspectives, 122, 754-760.

Saad, A., \& Hassanien, M. A. (2001). Assessment of arsenic level in the hair of the nonoccupational Egyptian population: Pilot study. Environment International, 27, 471-478.

Salama, A. K. (2016). Assessment of metals in cosmetics commonly used in Saudi Arabia. Environmental Monitoring and Assessment, 188, 11.

Sanderson, P., Delgado-Saborit, J. M., \& Harrison, R. M. (2014). A review of chemical and physical characterisation of atmospheric metallic nanoparticles. Atmospheric Environment, 94, 353-365.

Sanderson, P., Su, S. S., Chang, I. T., Saborit, J. D., Kepaptsoglou, D. M., Weber, R. J., \& Harrison, R. M. (2016). Characterisation of iron-rich atmospheric submicrometre particles in the roadside environment. Atmospheric Environment, 140, 167-175.

Sanna, E., Liguori, A., Palmas, L., Soro, M. R., \& Floris, G. (2003). Blood and hair lead levels in boys and girls living in two Sardinian towns at different risks of lead pollution. Ecotoxicology and Environmental Safety, 55, 293-299.

Satarug, S., \& Moore, M. R. (2004). Adverse health effects of chronic exposure to low-level cadmium in foodstuffs and cigarette smoke. Environmental Health Perspectives, 112, 1099-1103.

Sazakli, E., \& Leotsinidis, M. (2017a). Hair biomonitoring and health status of a general population exposed to Nickel. Journal of Trace Elements in Medicine and Biology: Organ of the Society for Minerals and Trace Elements (GMS), 43, 161-168.

Sazakli, E., \& Leotsinidis, M. (2017b). Hair biomonitoring and health status of a general population exposed to Nickel. Journal of Trace Elements in Medicine and Biology, 43, 161-168.

Ściskalska, M., Zalewska, M., Grzelak, A., \& Milnerowicz, H. (2014). The influence of the occupational exposure to heavy metals and tobacco smoke on the selected oxidative stress markers in smelters. Biological Trace Element Research, 159, 59-68.

Sepehri, M., Zokaei, M., Rezvani, M., \& Zarei, A. (2018). Comparison of the concentration of heavy metais in some vegetables (celery, broccoli and lettuce). Amazonia Investiga, 7, 324-334.

Shahsavani, S., Hoseini, M., Dehghani, M., \& Fararouei, M. (2017). Characterisation and potential source identification of polycyclic aromatic hydrocarbons in atmospheric particles (PM10) from urban and suburban residential areas in Shiraz, Iran. Chemosphere, 183, 557-564.

Shao, L., Chen, H., Zhang, C., \& Huo, X. (2017). Effects of major grassland conservation programs implemented in Inner Mongolia since 2000 on vegetation restoration and natural and anthropogenic disturbances to their success. Sustainability, 9, 466.

Skalny, A. V., Klimenko, L. L., Turna, A. A., Budanova, M. N., Baskakov, I. S., Savostina, M. S., Mazilina, A. N., Deyev, 
A. I., Skalnaya, M. G., \& Tinkov, A. A. (2017). Serum trace elements are interrelated with hormonal imbalance in men with acute ischemic stroke. Journal of Trace Elements in Medicine and Biology, 43, 142-147.

Skalny, A. V., Skalnaya, M. G., Tinkov, A. A., Serebryansky, E. P., Demidov, V. A., Lobanova, Y. N., Grabeklis, A. R., Berezkina, E. S., Gryazeva, I. V., Skalny, A. A., \& Nikonorov, A. A. (2015). Reference values of hair toxic trace elements content in occupationally non-exposed Russian population. Environmental Toxicology and Pharmacology, $40,18-21$

Skalny, A. V., Skalnaya, M. G., Tinkov, A. A., Serebryansky, E. P., Demidov, V. A., Lobanova, Y. N., Grabeklis, A. R., Berezkina, E. S., Gryazeva, I. V., Skalny, A. A., \& Skalnaya, O. A. (2015b). Hair concentration of essential trace elements in adult non-exposed Russian population. Environmental Monitoring and Assessment, 187, 1-8.

Soetrisno, F. N., \& Delgado-Saborit, J. M. (2020). Chronic exposure to heavy metals from informal e-waste recycling plants and children's attention, executive function and academic performance. Science of the Total Environment, $717,137099$.

Szynkowska, M. I., Marcinek, M., Pawlaczyk, A., \& Albińska, J. (2015). Human hair analysis in relation to similar environmental and occupational exposure. Environmental Toxicology and Pharmacology, 40, 402-408.

Tagesson, C., Källberg, M., \& Wingren, G. (1996). Urinary malondialdehyde and 8-hydroxydeoxyguanosine as potential markers of oxidative stress in industrial art glass workers. International Archives of Occupational and Environmental Health, 69, 5-13.

Tamburo, E., Varrica, D., \& Dongarrà, G. (2016). Gender as a key factor in trace metal and metalloid content of human scalp hair. A multi-site study. Science of the Total Environment, 573, 996-1002.

Teichert, F., Verschoyle, R. D., Greaves, P., Thorpe, J. F., Mellon, J. K., Steward, W. P., Farmer, P. B., Gescher, A. J., \& Singh, R. (2009). Determination of 8-oxo-2'-deoxyguanosine and creatinine in murine and human urine by liquid chromatography/tandem mass spectrometry: Application to chemoprevention studies. Rapid Communications in Mass Spectrometry, 23, 258-266.

Thorpe, A., \& Harrison, R. M. (2008). Sources and properties of non-exhaust particulate matter from road traffic: A review. Science of the Total Environment, 400, 270-282.

Toraason, M., Butler, M. A., Ruder, A., Forrester, C., Taylor, L., Ashley, D. L., Mathias, P., Marlow, K. L., Cheever, K. L., Krieg, E., \& Wey, H. (2003). Effect of perchloroethylene, smoking, and race on oxidative DNA damage in female dry cleaners. Mutation Research/genetic Toxicology and Environmental Mutagenesis, 539, 9-18.

Torghabeh, A. K., Jahandari, A., \& Jamasb, R. (2019). Concentration, contamination level, source identification of selective trace elements in Shiraz atmospheric dust sediments (Fars Province, SW Iran). Environmental Science and Pollution Research, 26, 6424-6435.

Varrica, D., Bardelli, F., Dongarrà, G., \& Tamburo, E. (2013). Speciation of $\mathrm{Sb}$ in airborne particulate matter, vehicle brake linings, and brake pad wear residues. Atmospheric Environment, 64, 18-24.

Varrica, D., Tamburo, E., Milia, N., Vallascas, E., Cortimiglia, V., De Giudici, G., Dongarrà, G., Sanna, E., Monna, F., \& Losno, R. (2014). Losno R Metals and metalloids in hair samples of children living near the abandoned mine sites of Sulcis-Inglesiente (Sardinia, Italy). Environmental Research, 134, 366-374.

Ventura, M. G., Freitas, M. D. C., \& Pacheco, A. M. (2005). Selenium levels in mainland Portugal. Water, Air, and Soil Pollution, 166, 167-179.

Venugopal, P., Halog, A., \& Dubey, B. K. (2016). Editorial special issue on E-waste management: E-waste: An urgent need to act. Management and Labour Studies, 41, vii-ix.

Vural, H., Demirin, H., Kara, Y., Eren, I., \& Delibas, N. (2010). Alterations of plasma magnesium, copper, zinc, iron and selenium concentrations and some related erythrocyte antioxidant enzyme activities in patients with Alzheimer's disease. Journal of Trace Elements in Medicine and Biology, 24, 169-173.

Wang, H., Zhang, Y., Liu, Q., Wang, F., Nie, J., \& Qian, Y. (2010). Examining the relationship between brominated flame retardants (BFR) exposure and changes of thyroid hormone levels around e-waste dismantling sites. International Journal of Hygiene and Environmental Health, 213, 369-380.

Wong, R. H., Kuo, C. Y., Hsu, M. L., Wang, T. Y., Chang, P. I., Wu, T. H., \& Huang, S. (2005). Increased levels of 8-hydroxy-2'-deoxyguanosine attributable to carcinogenic metal exposure among schoolchildren. Environmental Health Perspectives, 113, 1386-1390.

Yang, Q. Y., Qiu, X. H., Li, R., Ma, J., Li, K. Q., \& Li, G. (2015). Polycyclic aromatic hydrocarbon (PAH) exposure and oxidative stress for a rural population from the North China Plain. Environmental Science and Pollution Research, 22, 1760-1769.

Zanolin, M. E., Girardi, P., Degan, P., Rava, M., Olivieri, M., Di Gennaro, G., Nicolis, M., \& De Marco, R. (2015). Measurement of a urinary marker (8-hydroxydeoxy-guanosine, 8-OHdG) of DNA oxidative stress in epidemiological surveys: A pilot study. International Journal of Biological Markers, 30, E341-E345.

Zhu, Y., Wang, Y., Meng, F., Li, L., Wu, S., Mei, X., Li, H., Zhang, G., \& Wu, D. (2018). Distribution of metal and metalloid elements in human scalp hair in Taiyuan, China. Ecotoxicology and Environmental Safety, 148, 538-545.

Publisher's Note Springer Nature remains neutral with regard to jurisdictional claims in published maps and institutional affiliations. 